\title{
The Notch1 transcriptional activation domain is required for development and reveals a novel role for Notch1 signaling in fetal hematopoietic stem cells
}

\author{
Dawson M. Gerhardt, ${ }^{1,2,8}$ Kostandin V. Pajcini, ${ }^{1,2,8}$ Teresa D'altri, ${ }^{3}$ LiLi Tu, $^{1,2}$ Rajan Jain, ${ }^{4}$ \\ Lanwei Xu, ${ }^{1,2}$ Michael J. Chen, ${ }^{1,4}$ Stacey Rentschler, ${ }^{4}$ Olga Shestova, ${ }^{1,2}$ Gerald B. Wertheim, ${ }^{1,2}$ \\ John W. Tobias, ${ }^{2}$ Michael Kluk, ${ }^{5}$ Antony W. Wood, ${ }^{6}{ }^{7}$ Jon C. Aster, ${ }^{5}$ Phyllis A. Gimotty, ${ }^{7}$ \\ Jonathan A. Epstein, ${ }^{4}$ Nancy Speck, ${ }^{1,4}$ Anna Bigas, ${ }^{3}$ and Warren S. Pear ${ }^{1,2,9}$ \\ ${ }^{1}$ Abramson Family Cancer Research Institute, University of Pennsylvania, Philadelphia, Pennsylvania 19104, USA; ${ }^{2}$ Department \\ of Pathology and Laboratory Medicine, University of Pennsylvania, Philadelphia, Pennsylvania 19104, USA; ${ }^{3}$ Cancer Research \\ Program, Institut Hospital del Mar d'Investigacions Mèdiques, Hospital del Mar, Barcelona 08003, Spain; ${ }^{4}$ Department of Cell \\ and Developmental Biology, University of Pennsylvania, Philadelphia, Pennsylvania 19104, USA; ${ }^{5}$ Department of Pathology, \\ Brigham and Women's Hospital, Harvard Medical School, Boston, Massachusetts 02115, USA; ${ }^{6}$ Cell Signaling Technology, Inc., \\ Danvers, Massachusetts 01923, USA; ${ }^{7}$ Department of Epidemiology and Biostatistics, University of Pennsylvania, Philadelphia, \\ Pennsylvania 19104, USA
}

Notch1 is required to generate the earliest embryonic hematopoietic stem cells (HSCs); however since Notchdeficient embryos die early in gestation, additional functions for Notch in embryonic HSC biology have not been described. We used two complementary genetic models to address this important biological question. Unlike Notch1-deficient mice, mice lacking the conserved Notch1 transcriptional activation domain (TAD) show attenuated Notch1 function in vivo and survive until late gestation, succumbing to multiple cardiac abnormalities. Notch1 TAD-deficient HSCs emerge and successfully migrate to the fetal liver but are decreased in frequency by embryonic day 14.5. In addition, TAD-deficient fetal liver HSCs fail to compete with wild-type HSCs in bone marrow transplant experiments. This phenotype is independently recapitulated by conditional knockout of $R b p j$, a core Notch pathway component. In vitro analysis of Notch1 TAD-deficient cells shows that the Notch1 TAD is important to properly assemble the Notch1/Rbpi/Maml trimolecular transcription complex. Together, these studies reveal an essential role for the Notch1 TAD in fetal development and identify important cell-autonomous functions for Notch1 signaling in fetal HSC homeostasis.

[Keywords: Notch; hematopoietic stem cell; transcriptional activation domain]

Supplemental material is available for this article.

Received July 30, 2013; revised version accepted January 21, 2014.

Notch signaling is an evolutionarily conserved pathway that regulates binary cell fate decisions during fetal and adult development (Artavanis-Tsakonas et al. 1999). Signaling initiates when Notch receptors bind Notch ligands on a neighboring cell, leading to cleavage and nuclear translocation of the intracellular portion of Notch (ICN). Within the nucleus, Notch forms a transcriptional activation complex through interactions with the DNAbinding protein Rbpi and Mastermind (Maml), which functions as a coactivator via recruitment of the histone acetyltransferase p300 (Oswald et al. 2001; Fryer et al.

\footnotetext{
${ }^{8}$ These authors contributed equally to this work.

${ }^{9}$ Corresponding author

E-mail wpear@mail.med.upenn.edu

Article is online at http://www.genesdev.org/cgi/doi/10.1101/gad.227496.113.
}

2002; Nam et al. 2006; Kovall and Blacklow 2010). The assembly and function of the Notch transcription complex require multiple distinct intracellular Notch1 (ICN1) domains, which play specific roles in mediating Notch1 activity (Aster et al. 2000; Gordon et al. 2008; Kopan and Ilagan 2009). These include the RAM and Ankyrin repeat (ANK) domains. The RAM domain contains a high-affinity binding site for Rbpj, while the ANK domain forms weak contacts with Rbpi and is essential

(C) 2014 Gerhardt et al. This article is distributed exclusively by Cold Spring Harbor Laboratory Press for the first six months after the full-issue publication date (see http://genesdev.cshlp.org/site/misc/terms.xhtml). After six months, it is available under a Creative Commons License (Attribution-NonCommercial 4.0 International), as described at http:// creativecommons.org/licenses/by-nc/4.0/. 
for recruiting Maml (Nam et al. 2006; Wilson and Kovall 2006; Gordon et al. 2008). The C terminus of ICN1 contains a PEST sequence that modulates Notch protein degradation (Kovall and Blacklow 2010) and is frequently involved in loss-of-function mutations in human T-cell acute lymphoblastic leukemia (T-ALL) (Weng et al. 2004) and chronic lymphocytic leukemia (Puente et al. 2011). Between the ANK and PEST domains is the Notch transcriptional activation domain (TAD), which is capable of autonomous transcriptional activation (Kurooka et al. 1998; Kurooka and Honjo 2000; Fryer et al. 2002). Following formation of a functional transcriptional complex, Notch1 is subsequently phosphorylated in both the TAD and PEST domains by Maml-associated kinases, such as CDK8 (Fryer et al. 2004). Phosphorylation of these sites targets Notch1 for ubiquitination by ligases that include FBXW7 and ensuing proteasomal degradation (Fryer et al. 2002, 2004; O'Neil et al. 2007; Thompson et al. 2007).

Unlike the RAM, ANK, and PEST domains, which are highly conserved, the TAD shows substantial evolutionary divergence among the four mammalian Notch receptors. The Notch1 TAD is homologous to its Drosophila counterpart, while Notch2 contains a recognizable TAD whose activity is weaker than Notch1 (Kurooka et al. 1998). In contrast, Notch3 contains a TAD that shares minimal function and sequence conservation with the Notchl counterpart (Kurooka et al. 1998; Ong et al. 2006), while Notch4 lacks a TAD. The Notch1 TAD is required for optimal transcriptional activity of ICN1 in vitro and for ICN1-induced T-ALL in vivo (Aster et al. 2000). The Notch1 TAD directly interacts with the transcriptional coactivators PCAF and GCN5, and since these interactions also require the ANK domain (Kurooka et al. 1998; Kurooka and Honjo 2000), they are believed to augment Notch1-induced transcription by recruiting additional coactivators or stabilizing the association of p300 with the Notch transcriptional complex (Oswald et al. 2001; Fryer et al. 2002; Wallberg et al. 2002). However, study of the TAD has been limited to cell culture-based systems.

Notch1 exerts multiple essential roles in development. Loss of either Notch1 or components of the Notch signaling pathway leads to early embryonic demise associated with defects in vasculogenesis, somitogenesis, and cardiogenesis (Swiatek et al. 1994; Conlon et al. 1995; Lawson et al. 2001; Koo et al. 2005). Notch1 is also required between embryonic day 9.5 (E9.5) and E10.5 to generate the first definitive adult hematopoietic stem cells (HSCs) in the aorta-gonad-mesonephros (AGM) region (Kumano et al. 2003; Hadland et al. 2004). Definitive HSCs are defined by their ability to provide longterm, multilineage reconstitution (Dzierzak and Speck 2008). Shortly after generation, HSCs migrate to the fetal liver (FL), where they undergo a phase of dramatic expansion while retaining their capacity for long-term reconstitution (Morrison et al. 1995; Ema and Nakauchi 2000). Ultimately, HSCs migrate to the bone marrow (BM) in late gestation, where they persist, providing a continuous supply of blood cells through adulthood
(Dzierzak and Speck 2008). Since constitutive loss of Notch signaling results in major vascular defects and death by E10.5 (Krebs et al. 2000), it has been difficult to study Notch1 functions in fetal hematopoiesis after induction of the definitive HSCs. As Notch1 is not essential for adult HSC homeostasis (Mancini et al. 2005; Maillard et al. 2008), it is unclear whether Notch signaling provides important functions in HSCs subsequent to establishing the earliest definitive HSCs in the AGM.

In order to investigate the role of the Notch1 TAD in development, we generated Notch1 knock-in mice lacking the TAD. In contrast to Notch1-null mice, our mice lacking the Notch1 TAD $(\triangle T A D / \triangle T A D)$ frequently develop to late gestation and eventually succumb to multiple cardiovascular anomalies (High and Epstein 2007; High et al. 2009). We obtained viable $\triangle \mathrm{TAD} / \Delta \mathrm{TAD}$ embryos at E14.5 in order to investigate the requirement of the Notch1 TAD in FL hematopoiesis. Although the $\triangle \mathrm{TAD} / \triangle \mathrm{TAD}$ embryos have an intact hematopoietic system and HSCs successfully migrate from the AGM to the FL, the number of E14.5 FL HSCs in $\triangle \mathrm{TAD} / \Delta \mathrm{TAD}$ embryos was markedly reduced. Competitive transplants of highly purified long-term FL HSCs into lethally irradiated recipient mice revealed cell-intrinsic defects of the $\triangle \mathrm{TAD} / \triangle \mathrm{TAD}$ HSCs, a finding that was confirmed in $R b p i^{\mathrm{f} / \mathrm{f}} \times$ Vav-Cre conditional knockout mice. Our studies identify an important and novel function for Notch1 in fetal HSC homeostasis and highlight the role of the Notch1 TAD in mammalian development.

\section{Results}

\section{Generation of $\triangle T A D / \Delta T A D$ mice}

To determine the function of the Notch1 transactivation domain in vivo, we generated knock-in mice expressing a Notch1 mutant lacking the TAD ( $\triangle \mathrm{TAD} / \Delta \mathrm{TAD})$. We constructed a gene targeting vector by PCR-directed deletion of the 609-base-pair (bp) sequence encoding the TAD from the mouse Notch1 gene (Fig. 1A). The Notch1 $\triangle T A D$ knock-in mutation was achieved by homologous recombination of the targeting vector with the endogenous Notch1 gene in mouse embryonic stem cells. We verified deletion of the TAD by sequencing and PCR genotyping of genomic DNA from offspring (Fig. 1B). The level of Notch1 mRNA expression in mouse embryonic fibroblasts (MEFs) generated from $\triangle \mathrm{TAD} / \triangle \mathrm{TAD}$ and wild-type $(+/+)$ littermate controls was similar (Fig. 1C). In order to confirm that the deletion of the Notch1 TAD had the expected effect on the structure of the Notch1 protein, primary CD4 $\mathrm{T}$ cells from $+/+,+/ \Delta \mathrm{TAD}$, or $\Delta \mathrm{TAD} /$ $\triangle T A D$ FL transplant recipients were isolated and activated to stimulate Notch signaling. Immunoblotting for expression of cleaved Notch1 (Val1744) in nuclear extracts showed the presence of the $\sim 100-\mathrm{kD}$ band specific for cleaved Notch 1 in the $+/+$ and $+/ \Delta$ TAD T cells and an $\sim 80-\mathrm{kD}$ band in the $+/ \Delta \mathrm{TAD}$ and $\Delta \mathrm{TAD} / \Delta \mathrm{TAD} \mathrm{T}$ cells that is the expected size of a Notch1 protein bearing the $\triangle T A D$ mutation. Taken together, these results demonstrate that the $\triangle \mathrm{TAD}$ mutation did not impair transcrip- 


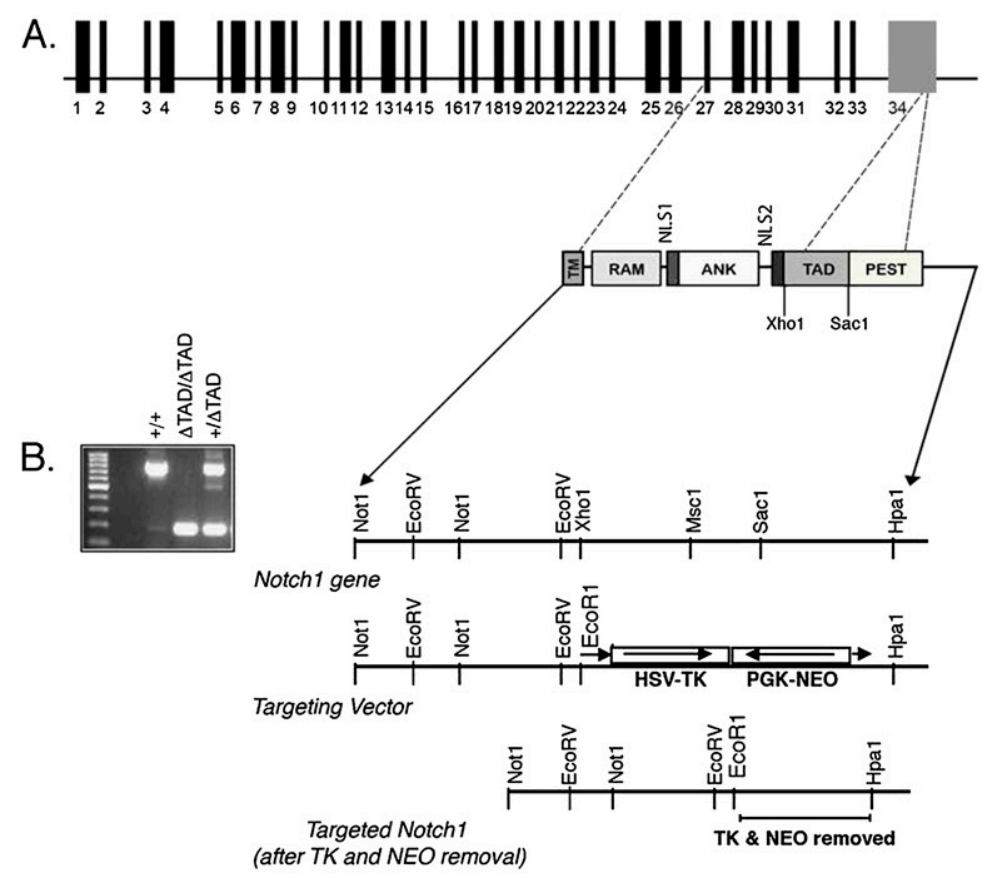

C.
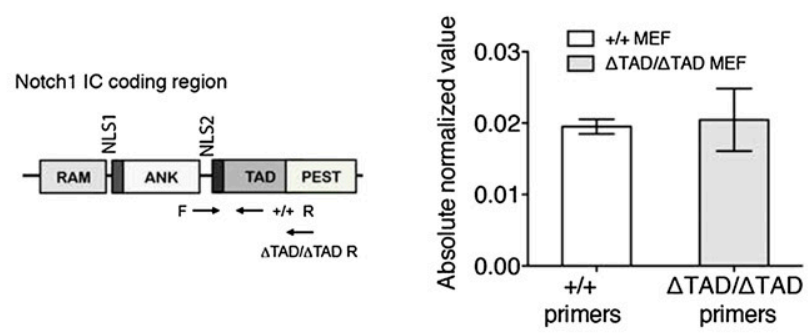

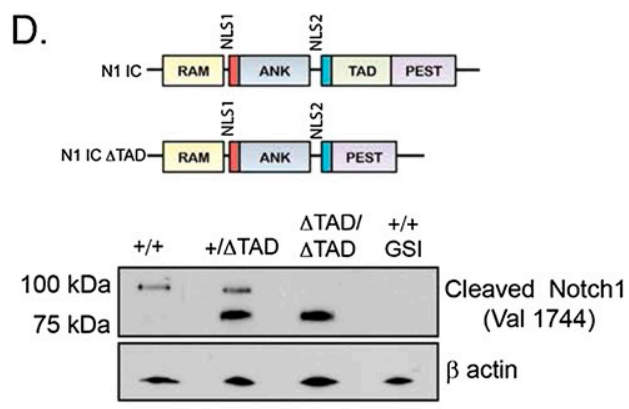

E.

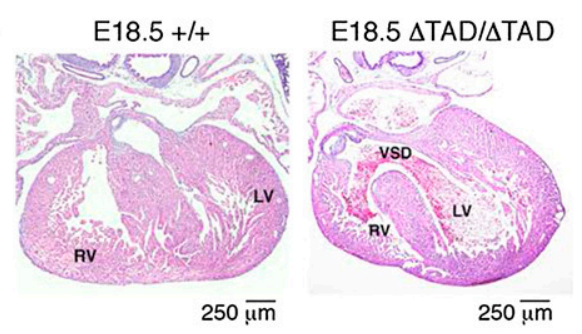

F.
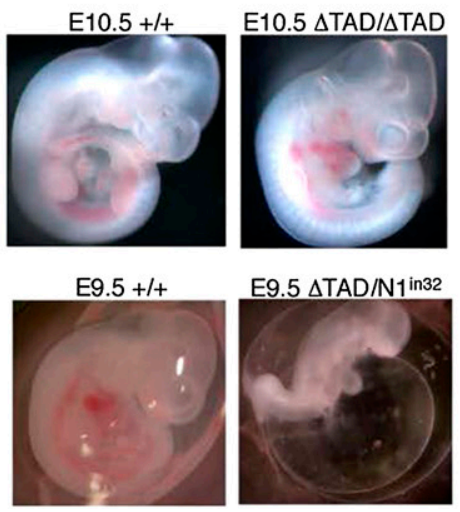

Figure 1. The Notch1 TAD deletion is a hypomorphic mutation. $(A)$ The Notch1 TAD was deleted by homologous recombination using a targeting vector designed to delete the genomic region of mouse Notchl corresponding to the TAD (extending roughly from a Xho site to a SacI site). (B) Deletion of the TAD (609 bp) was verified by PCR using primers flanking the TAD. (C) Loss of the Notch1 TAD does not affect Notch1 mRNA expression. mRNA was prepared from $+/+$ and $\triangle T A D / \Delta T A D$ MEFs and subsequently used for qPCR. Transcripts from $+/+$ and $\Delta \mathrm{TAD} / \Delta \mathrm{TAD}$ cells were amplified with unique primers. PCR products specific for $\Delta \mathrm{TAD} / \Delta \mathrm{TAD}$ transcripts yielded product below the limit of detection in $+/+$ cells. Primers specific for $+/+$ transcripts yielded product below the limit of detection in $\triangle \mathrm{TAD} / \triangle \mathrm{TAD}$ cells. " $\mathrm{F}$ " indicates forward primer, and " $\mathrm{R}$ " indicates reverse primer. $(D)$ Notchl expression. Nuclear extracts were prepared from splenic $\mathrm{CD} 4^{+} \mathrm{T}$ cells derived from transplanted $+/+,+/ \Delta \mathrm{TAD}$, and $\Delta \mathrm{TAD} / \Delta \mathrm{TAD}$ FL cells and were used for Western blot. Blots were probed with antibody specific for Notch1 cleaved at Val1744. $\beta$-Actin was the loading control. (E) Crosssections of wild-type and $\Delta \mathrm{TAD} / \Delta \mathrm{TAD}$ hearts at E18.5. The $\Delta \mathrm{TAD} / \Delta \mathrm{TAD}$ heart shows a ventricular septal defect (VSD). (RV) right ventricle; (LV) left ventricle. $(F)$ Deletion of the Notch1 TAD is a hypomorphic mutation. Notch $1^{+/ \text {in } 32}$ mice were bred with $+/ \Delta$ TAD to generate Notch $1^{\text {in32 }} / \Delta \mathrm{TAD}$ embryos. Notch ${ }^{\text {in32 }} / \Delta \mathrm{TAD}$ embryos were harvested at E9.5. Control embryos from $+/ \Delta \mathrm{TAD} \times+/ \Delta \mathrm{TAD}$ matings were harvested at E10.5. Normal gross development was observed in $\Delta \mathrm{TAD} / \Delta \mathrm{TAD}$ E10.5 mutant embryos. Retarded development and an enlarged pericardial sac were observed in Notch $1^{\text {in } 32} / \Delta \mathrm{TAD}$ embryos. See also Supplemental Figure S1.

tion, translation, cleavage, or nuclear localization of Notch1. However, the amount of $\triangle \mathrm{TAD}$ protein was increased relative to wild-type Notch1 protein (Fig. 1D). Given that the TAD mutation does not appear to influence mRNA levels (Fig. 1C), this difference likely stems from post-transcriptional factors.

Although the TAD deletion leaves intact PEST sequences that are known to influence Notch1 degradation, it is also believed that sequences in the TAD stimulate Notch1 protein turnover (Fryer et al. 2004; Chiang et al.
2006). We tested the relative stability of $\triangle \mathrm{TAD}$ and wildtype Notch1 proteins by looking at the rate of disappearance of the activated forms of these proteins in cells treated with a $\gamma$ secretase inhibitor (GSI), which blocks the generation of active Notch1. Immunoblot analysis conducted with $+/+,+/ \Delta \mathrm{TAD}$, and $\Delta \mathrm{TAD} / \Delta \mathrm{TAD}$ cells documented the existence of a long-lived pool of $\triangle \mathrm{TAD}$ protein in both the $+/ \triangle \mathrm{TAD}$ and $\triangle \mathrm{TAD} / \Delta \mathrm{TAD}$ cells (Supplemental Fig. S1A), suggesting that decreased turnover contributes to the accumulation of $\triangle \mathrm{TAD}$ protein. 


\section{$\triangle T A D$ is a hypomorphic Notch1 mutation}

No viable $\triangle \mathrm{TAD} / \triangle \mathrm{TAD}$ progeny were born by breeding heterozygous $(+/ \triangle \mathrm{TAD})$ adults, indicating the mutation resulted in death shortly after birth or during embryonic development (Table 1). Timed matings yielded $\Delta \mathrm{TAD} / \Delta \mathrm{TAD}$ embryos at expected Mendelian ratios at mid-gestation (E11.5). Genotypic analysis of E13.5-E14.5 litters revealed partial embryonic lethality of $\triangle \mathrm{TAD} / \Delta \mathrm{TAD}$ embryos (Table 1), although mutant embryos that were recovered at this time appeared grossly normal (Supplemental Fig. S1B). Histopathology of $\Delta \mathrm{TAD} / \triangle \mathrm{TAD}$ embryos that survived to late gestation (E18.5) revealed multiple cardiovascular defects, including abnormal outflow tract (OFT) development and ventricular septal defects (Fig. 1E). These cardiovascular abnormalities were similar to those caused by genetic or pharmacologic inhibition of the Notch pathway and are reminiscent of inhibiting Notch signaling in cardiac neural crest and second heart field myocardial precursors, both of which cause perinatal lethality (High et al. 2007, 2009). In contrast to $\triangle \mathrm{TAD} / \Delta \mathrm{TAD}$ embryos, $+/ \triangle T A D$ embryos were born at Mendelian ratios and appeared normal.

Although the failure of the Notch $1 \triangle \mathrm{TAD}$ retrovirus to induce T-cell leukemia in BM transplants (Aster et al. 2000) suggests that the Notch1 TAD deletion is a hypomorphic mutation, the increased amount of the $\triangle \mathrm{TAD}$ protein raised the possibility that the TAD deletion might actually enhance Notch1 function in vivo. To directly address this issue, we used a genetic approach in which Notch1 dose was titrated by crossing $+/ \Delta \mathrm{TAD}$ mice to mice heterozygous for loss of Notch1 function $\left(+/\right.$ Notch $1^{\text {in32) }}$ (Swiatek et al. 1994). We hypothesized that if the Notch1 TAD deletion was a hypomorphic mutation, then a further decrease in Notch signaling in $\Delta \mathrm{TAD} / \mathrm{Notch} 1^{\mathrm{in} 32}$ embryos would cause developmental abnormalities reminiscent of Notch1 loss-of-function mutations (Swiatek et al. 1994). Timed matings between $+/ \Delta T A D$ and $+/$ Notch $1^{\text {in32 }}$ produced embryos that were sacrificed at E9.5-E10.5, the time when mice with Notch1 loss-of-

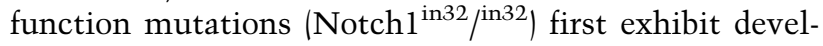
opmental defects (Swiatek et al. 1994; Oka et al. 1995). Three of the four possible genotypes from this mating develop normally, and at mid-gestation, the $+/+,+/ \Delta \mathrm{TAD}$, and Notch $1^{\text {in } 32} /+$ embryos were physiologically similar

Table 1. Genotype of pups born to $+/ \Delta \mathrm{TAD}$ interbreedings

\begin{tabular}{llcl}
\hline & $+/+$ & $+/ \Delta \mathrm{TAD}$ & $\Delta \mathrm{TAD} / \Delta \mathrm{TAD}$ \\
\hline E11.5 $(n=70)^{\mathrm{a}}$ & & & \\
$\quad$ Expected & 17.5 & 35 & 17.5 \\
$\quad$ Observed & 18 & 39 & 13 \\
E13.5-E14.5 $(n=293)^{\mathrm{b}}$ & & & \\
$\quad$ Expected & 75.75 & 151.5 & 75.75 \\
$\quad$ Observed & 73 & 173 & 47 \\
3 wk $(n=306)^{\mathrm{c}}$ & & & \\
$\quad$ Expected & 76.5 & 153 & 76.5 \\
Observed & 129 & 177 & 0 \\
\hline
\end{tabular}

${ }^{\mathrm{a}} \chi^{2}(2 \mathrm{df})=1.63, P$-value 0.443 .

${ }^{\mathrm{b}} \chi^{2}(2 \mathrm{df})=14.20, P$-value 0.0008 .

${ }^{\mathrm{c}} \chi^{2}(2 \mathrm{df})=116.3, P$-value $<0.0001$. and comparable with the $\triangle \mathrm{TAD} / \Delta \mathrm{TAD}$ embryos (Fig. $1 \mathrm{~F}$; data not shown). In contrast to their littermates and the $\Delta \mathrm{TAD} / \Delta \mathrm{TAD}$ embryos at E9.5, all embryos $(n=3)$ with a Notch1 loss of function on one allele and deletion of the Notch1 TAD on the other allele (Notch $1^{\text {in32 }} / \Delta T A D$ ) were developmentally stunted and had abnormal yolk sac vasculature and enlarged pericardial sacs, defects frequently seen in homozygous Notch1 loss-of-function mutants (Fig. 1F, bottom right image). We were unable to obtain Notch $1^{\text {in32/ }} / \Delta$ TAD embryos at E11.5, indicating that embryonic lethality occurred before E11.5. Further support for the hypomorphic nature of the Notch1 $\triangle \mathrm{TAD}$ was evident in the E18.5 $\Delta \mathrm{TAD} / \Delta \mathrm{TAD}$ thymus, in which the number of thymocytes and percentage of $\mathrm{CD} 4^{+} \mathrm{CD} 8^{+}$ double-positive (DP) T cells was significantly decreased compared with littermate controls (Supplemental Fig. S1C,D). Together, these data suggest that the TAD deletion produced a hypomorphic Notch1 allele.

\section{Notch1 signaling in FL HSCs}

Survival of the $\triangle \mathrm{TAD} / \triangle \mathrm{TAD}$ mice to $\mathrm{E} 14.5$ provided the opportunity to study Notch function in FL hematopoiesis, which was previously difficult to study in vivo due to the early embryonic death of Notch1-null mice. To characterize Notch1 signaling in FL HSCs, we measured Notch1 expression and signaling in E14.5 murine FL HSCs. Using a Notch $1 \mathrm{mAb}$ to measure Notch1 surface expression by flow cytometry (Fig. 2A), we confirmed the presence of Notch1 on the surface of E14.5 FL hematopoietic cells $\left(\mathrm{CD}^{+} 5^{+}\right.$) (Schmitt and Zuniga-Pflucker 2002; Fiorini et al. 2009). Beginning at E14.5, the surface markers Kit, Sca1, CD150, and CD48 and the absence of lineage markers can be used to stringently identify a population of long-term HSCs (LT-HSCs) (Kiel et al. 2005; Kim et al. 2006), referred to hereafter as SLAMLSKs ( Lin $\left.^{-} \mathrm{Scal}^{+} \mathrm{Kit}^{+} \mathrm{CD} 150^{+} \mathrm{CD} 48^{-}\right)$. Notch1 expression was greater on the LT-HSC-enriched CD $45^{+}$SLAM-LSKs than on the bulk population of hematopoietic cells $\left(\mathrm{CD} 45^{+}\right)$ (Fig. 2B).

Surface Notch1 expression marks cells with the potential to signal through Notch 1 but does not measure active Notch1 signaling. Since Notch1 cleavage is a prerequisite for Notch1 activation, measuring cleaved ICN1 is a more accurate indication of Notch activity. We used intracellular flow cytometry to measure the cleaved Notch1 intracellular peptide in E14.5 FL SLAM-LSK LT-HSCs (Fig. 2C). The level of expression in FL HSCs was similar to expression in DN3 thymocytes, a population known to have robust Notch signaling, and higher than in both DP thymocytes and BM SLAM-LSKs, which are populations known to have low Notch activity (Fig. 2D; Huang et al. 2003; Maillard et al. 2008; Fiorini et al. 2009; YashiroOhtani et al. 2009).

To measure downstream events of Notch cleavage and further validate Notch activity, we quantified expression of the direct Notch target Hes1 in sorted hematopoietic cells (Fig. 2E). Consistent with previous studies, Hes1 mRNA was present at high levels in DN3 thymocytes and low levels in DP thymocytes and BM SLAM-LSKs (Maillard 
Gerhardt et al.

A.

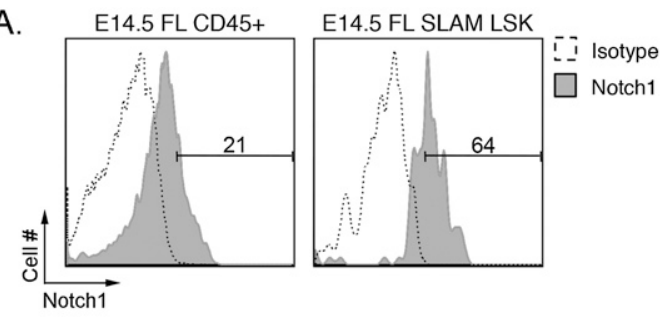

C.
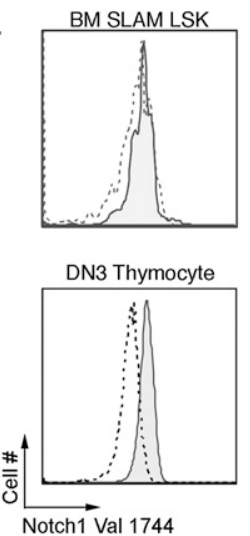

B.

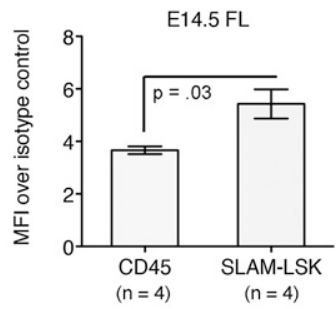

D.

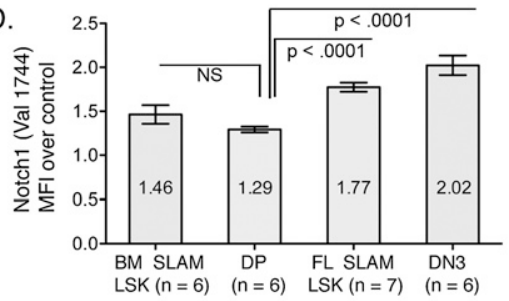

E.

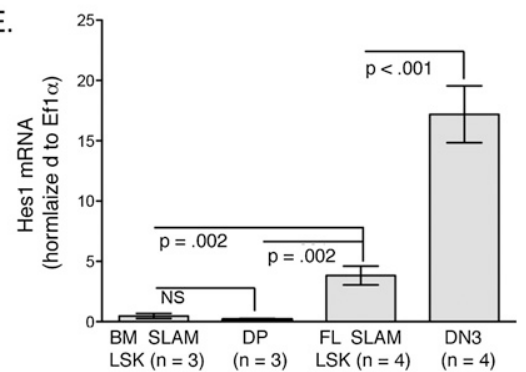

Figure 2. Notch1 signaling in the E14.5 FL. $(A)$ Notch1 is expressed on the surface of FL hematopoietic progenitors and HSCs. E14.5 FLs from wild-type B6 embryos were stained for SLAM-LSK markers and Notch1 or isotype control antibody. Flow cytometry plots are representative of three independent experiments. (B) Average fold mean fluorescent intensity (MFI) of Notch1-expressing E14.5 FL hematopoietic cells $\left(\mathrm{CD}^{+} 5^{+}\right)$and SLAM-LSKs over isotype control. $(C)$ Notch1 is cleaved in E14.5 FL HSCs (CD45 ${ }^{+}$SLAM-LSKs). Wildtype DN3 thymocytes, DP thymocytes, and BM SLAM-LSKs were used as additional controls for detection of cleaved Notch1. Following surface staining, cells were fixed, permeabilized, and stained for ICN1 (Val1744). (D) Graph represents average fold MFI of ICN1 over background staining. $(E)$ Expression of Hes1 mRNA in sorted hematopoietic cells. All values were normalized to Ef1 $\alpha$. Populations are similar to $C$.

et al. 2008; Yashiro-Ohtani et al. 2009). We detected significantly higher expression of Hes1 in E14.5 FL SLAMLSKs compared with DP thymocytes and BM SLAMLSKs, although the level was not as high as in DN3 thymocytes. These data are consistent with a recent study using a GFP allele knocked into the murine Hes1 locus, which showed higher levels of Hes1 expression in FL HSCs compared with more differentiated FL progenitors and BM HSCs (Oh et al. 2013). Together, these data demonstrate that Notch1 is activated in FL HSCs and point to a possible physiologic role for Notch signaling in the FL.

\section{The Notch1 TAD is not required for HSC emergence}

Survival of the $\Delta \mathrm{TAD} / \Delta \mathrm{TAD}$ mice to mid-gestation provided the opportunity to investigate the functional effect of Notch signaling on several crucial stages of embryonic HSC development, including hemogenic endothelium differentiation, migration of HSCs to the FL, and expansion, survival, and maturation in the FL. As Notch1 is required to generate the first definitive LT-HSCs, we investigated the effect of the Notch1 TAD deletion on the generation of embryonic HSCs. To address this, we analyzed phenotypic HSCs in the AGM, which at E11.5 are found within a population of clustered hematopoietic cells that coexpress the endothelial marker CD144 (VEcadherin) and the pan-hematopoietic marker CD45 (North et al. 2002; Taoudi et al. 2005). The numbers of CD $144^{+} \mathrm{CD} 45^{+}$cells were similar in the AGM and FL of $+/+,+/ \Delta \mathrm{TAD}$, and $\Delta \mathrm{TAD} / \Delta \mathrm{TAD}$ E11.5 embryos (Fig. $3 \mathrm{~A}, \mathrm{~B})$. An alternative method of assessing emerging phenotypic HSCs in the AGM relies on the identification of cells that coexpressed Kit and CD31. The $\mathrm{Kit}^{+} \mathrm{CD} 31^{+}$ cells of the AGM from the $\triangle \mathrm{TAD} / \Delta \mathrm{TAD}$ E11.5 embryos were similar in number to wild-type littermates (Supplemental Fig. S2A; Yokomizo and Dzierzak 2010). These data suggest that the Notch1 TAD is unnecessary for either the emergence of embryonic HSCs or their migration to the FL.

\section{Notch1 $\triangle T A D$ FL LT-HSCs exhibit survival defects}

After migration to the FL, HSCs continue their maturation and expansion (Ema and Nakauchi 2000; Kieusseian et al. 2012). We next asked whether $\Delta \mathrm{TAD} / \Delta \mathrm{TAD} F L$ 
A.

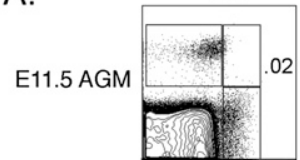

E11.5 FL

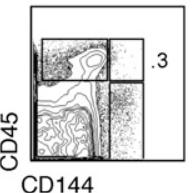

C.

E14.5 FL SLAM LSK
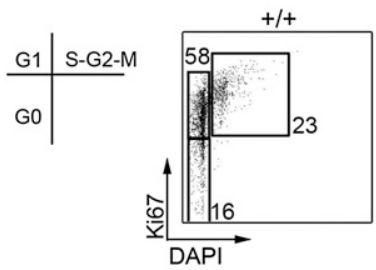

E.

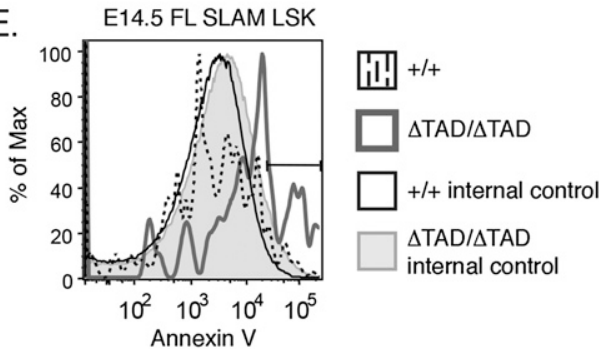

B.
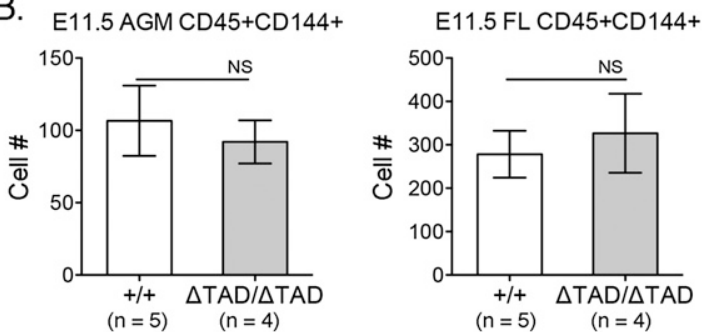

D.

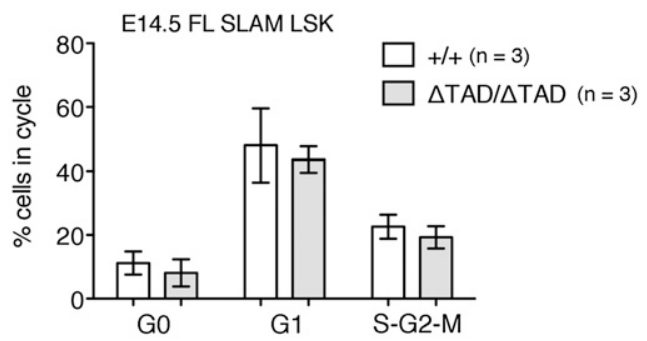

F.

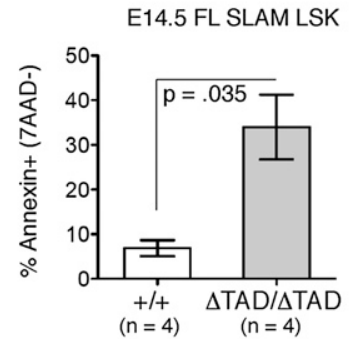

Figure 3. Increased apoptosis in FL $\triangle \mathrm{TAD} / \Delta \mathrm{TAD}$ LT-HSCs. (A) Flow cytometry analysis of E11.5 AGM regions and E11.5 FLs from +/+ and $\triangle \mathrm{TAD} / \Delta \mathrm{TAD}$ embryos. Cells were gated on $7-\mathrm{AAD}^{-} \mathrm{TER}^{-} 119^{-}$populations. Endothelial cells were identified as $\mathrm{CD} 144^{+}$, hematopoietic progenitors are $\mathrm{CD} 45^{+}$, and HSCs are $\mathrm{CD} 45^{+} \mathrm{CD} 144^{+} .(B)$ Absolute numbers of cells gated as $\mathrm{CD} 45^{+} \mathrm{CD} 144^{+}($as depicted in $A$ ) in E11.5 AGM regions and E11.5 FLs from three independent experiments. $(C)$ Cell cycle analysis of $+/+$ and $\Delta$ TAD/ $\Delta$ TAD E14.5 FL SLAM-LSKs. Representative flow cytometry plot of the cell cycle by DAPI and Ki-67. $(D)$ The bar graph represents percentages of SLAM-LSKs in each cell cycle stage from three independent experiments. (E) Increased apoptosis in $\triangle \mathrm{TAD} / \triangle \mathrm{TAD}$ E14.5 FL SLAMLSKs. Representative flow cytometry plots of Annexin $\mathrm{V}^{+}$cells from $+/+$(dotted line) and $\Delta \mathrm{TAD} / \Delta \mathrm{TAD}$ (bold gray line) E14.5 FL SLAMLSKs. Annexin V expression on internal control $\mathrm{Lin}^{+}$cells of $+/+$(solid black line) and $\Delta \mathrm{TAD} / \Delta \mathrm{TAD}$ (light-gray shading) was used to determine the positive gate for Annexin $\mathrm{V}$ staining. $(F)$ The bar graph represents the normalized percentage of Annexin $\mathrm{V}^{+} 7-\mathrm{AAD}^{-}$cells from E14.5 +/+ and $\Delta \mathrm{TAD} / \Delta \mathrm{TAD}$ FL SLAM-LSKs $(n=4)$. Values were determined by subtracting the mean percentage of $+/+$ Annexin $\mathrm{V}^{+}$Lin $^{+}$cells (calculated as percent Annexin $\mathrm{V}^{+}$cells $\pm \mathrm{SEM}$, which was $1.600 \pm 0.147 ; n=4$ ) from the mean percentage of Annexin $\mathrm{V}^{+}$ $+/+$ SLAM-LSKs and by subtracting the mean percentage of $\Delta \mathrm{TAD} / \Delta \mathrm{TAD}$ Annexin $\mathrm{V}^{+} \mathrm{Lin}^{+}$cells $(4.025 \pm 0.728 ; n=4)$ from the mean percentage of Annexin $\mathrm{V}^{+} \Delta \mathrm{TAD} / \Delta \mathrm{TAD}$ SLAM-LSKs.

HSCs exhibited defects in growth and/or survival. We tested the capacity of $\Delta \mathrm{TAD} / \Delta \mathrm{TAD}$ FL cells to progress through the cell cycle by labeling with DAPI and Ki67. We observed no defects of cell cycle entry or progression of $\triangle \mathrm{TAD} / \Delta \mathrm{TAD}$ FL SLAM-LSKs or LSKs (Fig. 3C,D; Supplemental Fig. 2B). To assess survival, we measured 7-AAD and Annexin V expression in FL SLAM-LSKs from $+/+$ and $\Delta \mathrm{TAD} / \Delta \mathrm{TAD}$ embryos (Fig. $3 \mathrm{E}, \mathrm{F}$ ). The percentage of early apoptotic (7-AAD ${ }^{-} /$Annexin $\mathrm{V}^{+}$) SLAM-LSKs was significantly increased in $\triangle \mathrm{TAD} / \Delta \mathrm{TAD}$ FL cells compared with +/+ FL cells (Fig. 3F). We observed a similar increase in Annexin $\mathrm{V}$ in $\Delta \mathrm{TAD} / \Delta \mathrm{TAD}$ LSKs (Supplemental Fig. S2C). These data suggest that signaling involving the Notch1 TAD contributes to FL LT-HSC survival but not to the proliferation of these cells. Analysis of FL histology among littermates indicated that while total FL cellularity was reduced in E14.5 $\Delta \mathrm{TAD} / \Delta \mathrm{TAD}$ FLs, gross structural abnormalities were not evident (Supplemental Fig. S2DE). Because the $\triangle \mathrm{TAD}$ mutation is constitutive, we cannot exclude the possibility that non-cell-autonomous defects in the FL niche contribute to the observed decrease in HSC survival.

FL transplants indicate a role for the Notch1 $\triangle T A D$ in HSC development

To investigate the role of the Notch1 TAD in HSC function, we performed FL transplants from E14.5 $\Delta$ TAD/ $\Delta$ TAD embryos. Unsorted E14.5 FL cells from $+/ \Delta \mathrm{TAD}$ or $\Delta \mathrm{TAD} / \Delta \mathrm{TAD}\left(\mathrm{C} 57 \mathrm{BL} / 6 \mathrm{CD} 45.2^{+}\right)$were trans- 
planted into congenic, lethally irradiated SJL (B6-Ly5.2/ Cr CD45. $1^{+}$) recipients (Fig. 4A). B-cell, T-cell, and myeloid lineages were present in recipients of $\Delta \mathrm{TAD} / \Delta \mathrm{TAD}$ E14.5 FL cells; however, there was a partial block in thymocyte development from the $\mathrm{CD} 4^{-} \mathrm{CD} 8^{-}$doublenegative (DN) to the $\mathrm{CD} 4^{+} \mathrm{CD} 8^{+} \mathrm{DP}$ stage, as evidenced by decreases in the percentage and absolute numbers of thymic CD45.2-derived cells (Fig. 4B; Supplemental Fig. S3A,B). We also observed decreased percentages of $\mathrm{CD}^{+}$ and $\mathrm{CD} 8^{+} \mathrm{T}$ cells in the peripheral blood but did not find differences in the number or percentage of splenic CD19 ${ }^{+}$ or $\mathrm{Gr}^{+}$cells (Fig. 4B; Supplemental Fig. S3A,B). The Tcell findings were reminiscent of conditional Notch1 and Rbpi knockout alleles (Wolfer et al. 2002; Tanigaki et al. 2004) and consistent with the hypomorphic nature of the $\triangle \mathrm{TAD}$ allele.
While multilineage reconstitution of recipient mice verified the existence of HSCs in the FLs of $\Delta \mathrm{TAD} / \Delta \mathrm{TAD}$ donors, the percentage and absolute numbers of CD45.2 $2^{+}$ cells in the BM were significantly reduced when compared with reconstitution by $+/+$ and $+/ \Delta$ TAD FL littermate controls (Fig. 4C, Supplemental Fig. S3B,C). It is unlikely that the decrease of $\Delta \mathrm{TAD} / \Delta \mathrm{TAD}$-derived cells in the periphery was due to aberrant HSC self-renewal at the expense of progenitor differentiation or retention of cells in the BM, as CD45.2 $2^{+}$HSCs did not accumulate in the BM of recipient mice (Supplemental Fig. S3D). The ability of $\triangle \mathrm{TAD} / \Delta \mathrm{TAD}$ HSCs to home to recipient BM and give rise to cells of multiple blood lineages demonstrates that functional HSCs can be generated even in the absence of the TAD, although loss of the TAD may negatively impact the efficiency of repopulation and/or
A.

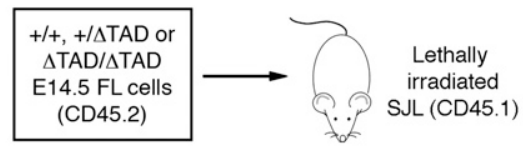

B.
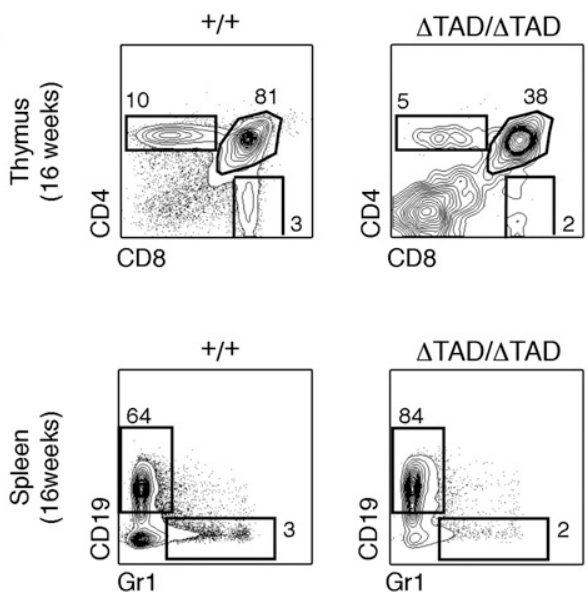

C.

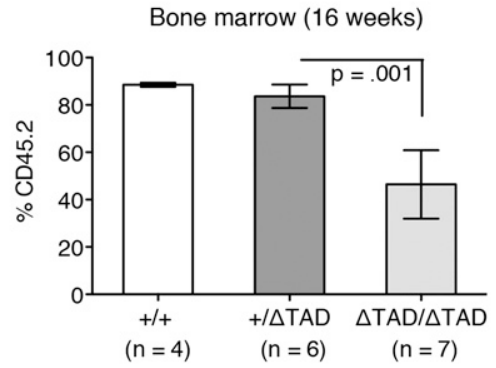

D.
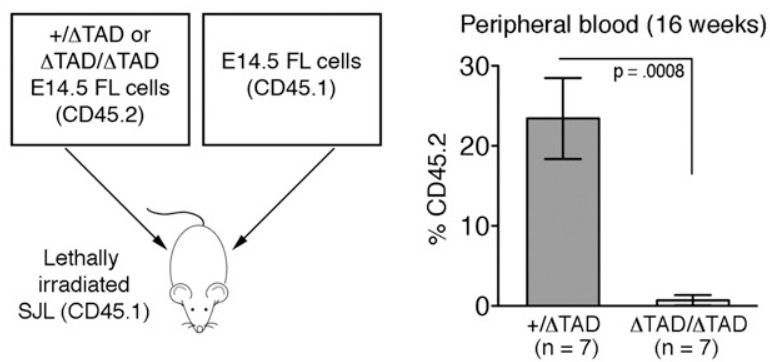

E.
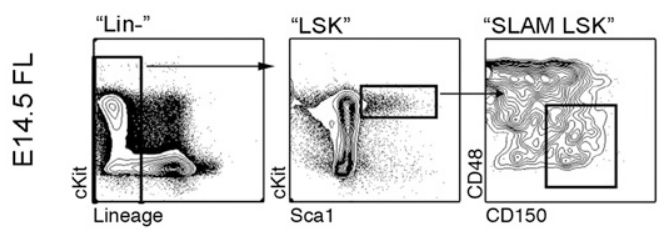

F.
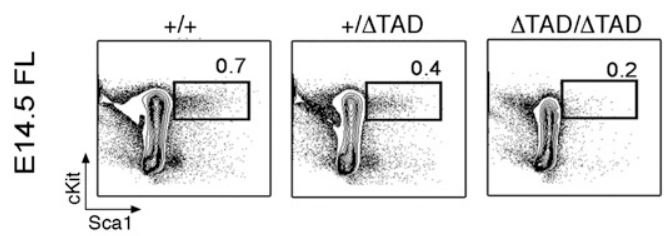

G.
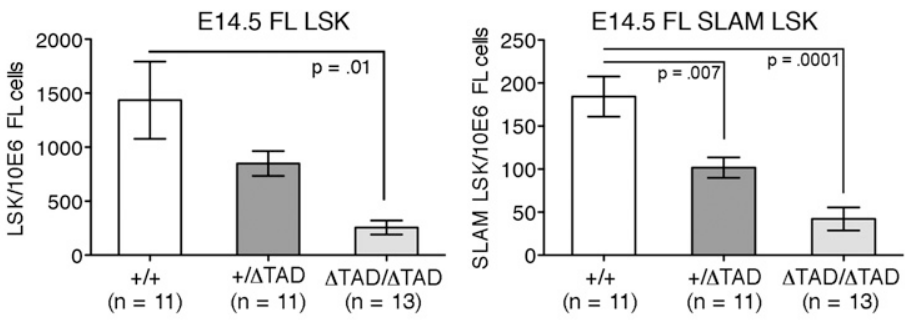

Figure 4. Competitive defects and reduced LT-HSC frequency in $\triangle \mathrm{TAD}$ FL HSCs. (A) Schematic for noncompetitive E14.5 FL transplants. $(B)$ Multilineage reconstitution of primary recipients by $\Delta \mathrm{TAD} / \Delta \mathrm{TAD}$ E14.5 FL cells. Representative flow cytometry plots from the thymus and spleen of $+/+$ or $\Delta \mathrm{TAD} / \Delta \mathrm{TAD}$ reconstituted recipients at $16 \mathrm{wk} .(C)$ E14.5 FL cells $\left(2 \times 10^{6}\right)$ from $\mathrm{B} 6\left(\mathrm{CD} 45.2^{+}\right)+/+$, $+/ \Delta \mathrm{TAD}$, or $\Delta \mathrm{TAD} / \Delta \mathrm{TAD}$ embryos were transplanted into lethally irradiated SJL $\left(\mathrm{CD} 45.1^{+}\right)$recipients. Bar graph represents mean reconstitution at $16 \mathrm{wk}$ in $\mathrm{BM}$, measured by the percentage of CD45.2 ${ }^{+}$cells. $(D)$ E14.5 FL cells $\left(1 \times 10^{6}\right)$ from $\mathrm{B} 6\left(\mathrm{CD} 45.2^{+}\right)+/ \Delta \mathrm{TAD}$ or $\Delta \mathrm{TAD} / \Delta \mathrm{TAD}$ embryos were transplanted in competition with $1 \times 10^{6}$ wild-type CD $45.1^{+} \mathrm{E} 14.5 \mathrm{FL}$ cells into lethally irradiated SJL CD45.1 recipients. The bar graph represents mean reconstitution at $16 \mathrm{wk}$ in peripheral blood, measured by the percentage of CD45.2 cells. (E) SLAM-LSK gating strategy to identify LT-HSCs. (F) Percentage of LSK from $+/+,+/ \Delta$ TAD, or $\Delta \mathrm{TAD} / \Delta \mathrm{TAD}$ E14.5 FL cells. All cells were first gated on DAPI ${ }^{-}$CD $45.2^{+}$. $(G)$ Number of LSKs (left panel) and SLAM-LSKs (right panel) per $10^{6}$ cells from $+/+,+/ \Delta$ TAD, or $\Delta \mathrm{TAD} / \Delta \mathrm{TAD}$ E14.5 FLs. 
function. To further explore defects in the $\Delta \mathrm{TAD} / \Delta \mathrm{TAD}$ FL HSCs, we performed competitive whole FL transplants, which test the ability of these cells to compete against wild-type FL counterparts. We transplanted unfractionated FL cells from E14.5 +/DTAD or $\Delta$ TAD/ $\Delta \mathrm{TAD}\left(\mathrm{CD} 45.2^{+}\right)$at a $1: 1$ ratio with competitor CD45.1 $1^{+}$ E14.5 FL cells. When compared with reconstitution by $+/ \Delta$ TAD FL cells, we observed minimal contribution to the peripheral blood hematopoietic compartment from $\Delta \mathrm{TAD} / \Delta \mathrm{TAD}$ FL cells (Fig. 4D).

The observed defects in both the noncompetitive and competitive transplants of $\Delta \mathrm{TAD} / \Delta \mathrm{TAD}$ FL cells could be due to several developmental abnormalities, such as decreased numbers of HSCs, impaired HSC function, or a combination of both. To investigate these possibilities, we first assessed the frequency of $\Delta \mathrm{TAD} / \Delta \mathrm{TAD}$ FL HSCs by flow cytometric analysis of cells expressing SLAMLSK markers (Fig. 4E). We observed a striking reduction in the $\Delta \mathrm{TAD} / \Delta \mathrm{TAD}$ FL LSK and SLAM-LSK cells in the CD $45^{+}$population (Fig. 4F, G; Kiel et al. 2005). The dramatic decrease in the SLAM-LSK HSCs in the $\triangle \mathrm{TAD} / \Delta \mathrm{TAD} F \mathrm{~F}$ provides a potential explanation for the competitive disadvantage observed in the whole FL transplants.

\section{Competitive SLAM-LSK FL transplants reveal cell-intrinsic defects in $\triangle T A D / \triangle T A D$ FL HSCs}

Although the $\Delta \mathrm{TAD} / \Delta \mathrm{TAD}$ FL HSCs exhibited reconstitution defects at the population level, it was critical to determine whether this defect was due to a cell-intrinsic shortcoming in the HSC population or other potential developmental abnormalities. We thus performed competitive transplants with purified CD45.2 $2^{+}$SLAM-LSKs from the FLs of E14.5 +/+, +/ $\Delta$ TAD, and $\Delta \mathrm{TAD} / \Delta \mathrm{TAD}$ littermates (Fig. 4E). To simplify the description of the experiments, CD45.2+ FL SLAM-LSKs are henceforth referred to as donor cells. For competitor cells, we sorted CD 45. $1^{+/}$CD 45.2 $2^{+}$SLAM-LSKs from adult BM. SJL (B6Ly5.2/Cr CD45. $1^{+}$) mice were lethally irradiated and transplanted with 350 donor FL CD45.2 $2^{+}$SLAM-LSKs and 350 BM competitor CD45. $1^{+} / \mathrm{CD} 45.2^{+}$BM SLAM-LSKs, along with a protective dose of helper splenocytes (Fig. 5A). The
A.

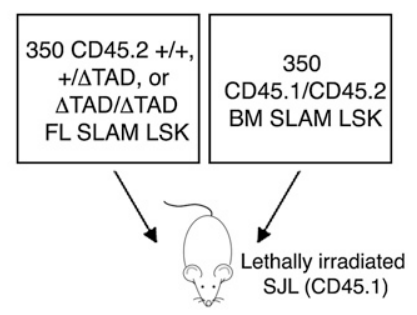

B.

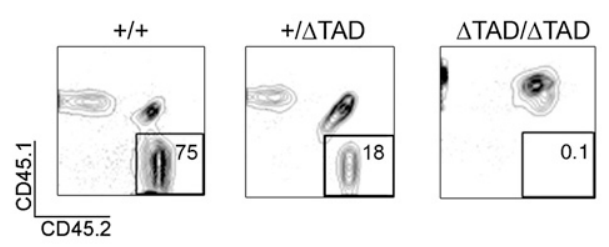

C.

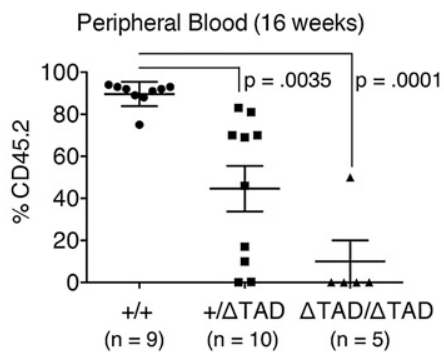

D.

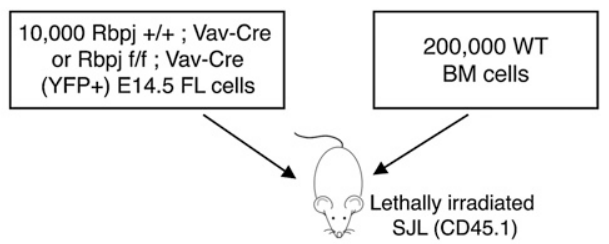

E.

Peripheral blood (16 weeks)

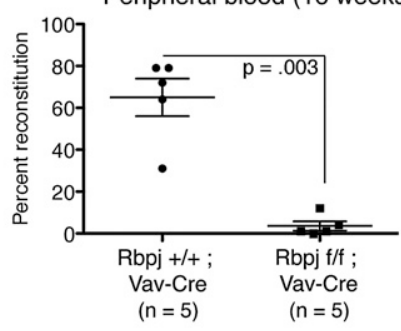

F.

BM (16 weeks)

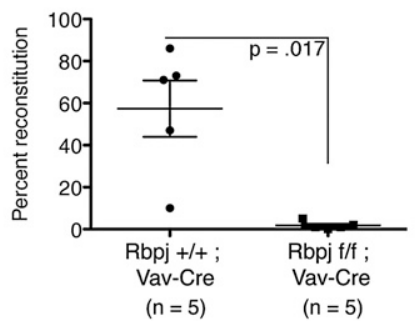

Figure 5. Impaired competitive reconstitution by Notch1 TAD-deficient FL HSCs and Rbpj-deficient FL cells. (A) Schematic

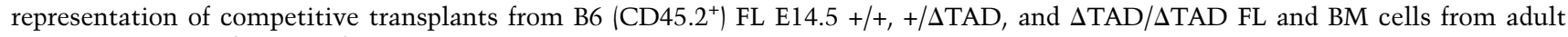
B6/SJL F1 $\left(\mathrm{CD}^{2} 5.1^{+} / \mathrm{CD} 45.2^{+}\right)$mice were FACS-sorted for SLAM-LSK. Three-hundred-fifty FL SLAM-LSKs and 350 BM SLAM-LSKs were transplanted in competition $(1: 1)$ into lethally irradiated CD45.1 $1^{+}$recipients. $(B)$ Representative flow cytometry plots from peripheral blood ( 16 wk post-transplant) of recipients showing reconstitution by CD $45.2^{+}$cells. $(C)$ Donor cell reconstitution at week 16 was measured by CD $45.2^{+}$percentage in peripheral blood of recipients. The plot of data points is from five independent experiments. $(D)$ Competitive reconstitution of Rbpj-deficient FL hematopoietic cells. E14.5 FL cells from $R b p i^{\mathrm{f} / \mathrm{f}}$; Vav-Cre Rosa26YFP and $R b p j^{+/+}$; Vav-Cre Rosa26YFP control embryos were transplanted in competition with CD45. $1^{+} / \mathrm{CD} 45.2^{+}$adult BM cells at a ratio of $10,000 \mathrm{FL}$ cells:200,000 BM cells. $(E, F)$ Donor cell reconstitution was measured by the percentage of $\mathrm{YFP}^{+}$cells in the blood $(E)$ and BM $(F)$ at 16 wk post-transplant. 
reconstitution capacity of the donor cells was defined by the percentage of CD45.2 $2^{+}$cells in the peripheral blood of transplant recipients. We found that the $\triangle \mathrm{TAD} / \Delta \mathrm{TAD} F \mathrm{FL}$ SLAM-LSKs were markedly deficient in reconstituting irradiated hosts in the face of competition with normal BM SLAM-LSKs (Fig. 5B,C) Consistent with this result, we observed a reciprocal increase in competitor CD45. $1^{+} /$CD $45.2^{+}$cells (Supplemental Fig. S4A). To confirm that $\triangle \mathrm{TAD} / \triangle \mathrm{TAD}$ FL HSCs were present in the populations selected for study, we transplanted unsorted and LSK-depleted cells from $\Delta \mathrm{TAD} / \Delta \mathrm{TAD}$ FLs directly into irradiated recipients. Unsorted $\triangle \mathrm{TAD} / \Delta \mathrm{TAD}$ FL cells provided multilineage reconstitution, while $+/+$ and $\Delta \mathrm{TAD} / \Delta \mathrm{TAD}$ FLs depleted for LSK cells did not (Supplemental Fig. S4B). In addition to the $\triangle \mathrm{TAD} / \Delta \mathrm{TAD}$ FL cells, the $+/ \Delta$ TAD SLAM-LSK FL cells also significantly underperformed in competitive reconstitution assays (Fig. 5B,C).

As these data suggested an important cell-autonomous defect in HSC function in the $\triangle \mathrm{TAD} / \triangle \mathrm{TAD}$ mice, we performed secondary BM transplants in mice that had received unfractionated E14.5 FL cells (Fig. 4A-C). Donorderived (either $\triangle \mathrm{TAD} / \Delta \mathrm{TAD}$ or $+/+$ ) CD45.2 $2^{+}$SLAM-LSKs were sorted from the BM of primary recipients $16 \mathrm{wk}$ post-transplant, and 1000 CD45.2 $2^{+}$SLAM-LSKs were transferred into secondary irradiated hosts. When we analyzed the peripheral blood of the secondary hosts for the presence of CD45.2 $2^{+}$cells, we found a significant decrease in the ability of the $\triangle \mathrm{TAD} / \triangle \mathrm{TAD}$ SLAM-LSKs to reconstitute the secondary hosts (Supplemental Fig. S4C,D). These data suggest that Notch1, via the TAD, is required for both the survival of emergent HSCs after migration to the FL and optimal function of FL HSCs in the transplant setting.

\section{Competitive transplants reveal cell-intrinsic defects in Rbpi ${ }^{f / f} \times$ Vav-Cre FL HSCs}

Our findings in the Notch1 $\triangle T A D$ model suggested that Notch1 is critical for FL HSC homeostasis. To verify this finding, we used a second genetic model in which Rbpj is conditionally deleted in fetal HSCs. Rbpj is the DNAbinding protein that mediates Notch-dependent transcriptional activation (Tamura et al. 1995), and constitutive loss of Rbpj mirrors loss of Notch function (Oka et al. 1995). Specific hematopoietic deletion of Rbpj was attained by breeding mice with floxed $R b p i$ alleles to mice expressing Cre recombinase under the regulation of Vav1 genetic elements. Vav1 expression is restricted to hematopoietic cells, and the Vav-Cre transgene becomes active between E12.5 and E14.5 (Ogilvy et al. 1999; Stadtfeld and Graf 2005), thus restricting the deletion of Rbpi to hematopoietic cells after HSC emergence without affecting embryonic survival or the generation of Notch1-dependent HSC precursors. We performed a transplant of 10,000 unsorted E14.5 FL cells from $\mathrm{Rbpj}^{+/+}$; Vav-Cre Rosa26YFP or $R b p i^{\mathrm{f} / \mathrm{f}}$; Vav-Cre Rosa26YFP embryos in competition with 200,000 congenic BM competitors (Fig. 5D). Consistent with the competitive transplants of the $\Delta \mathrm{TAD} / \Delta \mathrm{TAD}$ FL HSCs, $R b p i^{f / f}$; Vav-Cre FL cells exhibited a competitive reconstitution defect, as indicated by the low percentage of $\mathrm{YFP}^{+}$cells in the peripheral blood or BM of transplant recipients $16 \mathrm{wk}$ post-transplant (Fig. 5E,F). These results confirm a novel and specific cell-intrinsic role for Notch signaling in FL HSC function.

\section{Notch1 TAD loss impairs formation of the Notch transcriptional activation complex}

Because the Notch1 TAD is important for optimal transcription, we hypothesized that loss of the TAD results in decreased transcription of Notch target genes in cells from $\triangle \mathrm{TAD} / \triangle \mathrm{TAD}$ embryos. To begin to test this hypothesis, we retrovirally expressed ICN1 $\triangle$ TAD in 8946 $\mathrm{T}$ cells, which depend on a conditional human MYC transgene for growth. We previously showed that 8946 cells are rescued from MYC withdrawal by retroviral expression of ICN1 via up-regulation of endogenous Notch target genes, including murine Myc (Weng et al. 2006). As compared with wild-type ICN1, expression of multiple ICN1 targets, including CD25, Notch1, Notch3, Dtx1, Ptcra, and Myc, was decreased in 8946 cells following ICN1 $\triangle \mathrm{TAD}$ expression, a result consistent with the decreased activity of ICN1 $\triangle T A D$ in luciferase reporter gene assays (Supplemental Fig. 5A-C).

Although multiple direct targets of Notch1 in T cells are known, the identity of genes directly regulated by Notch in fetal HSCs is largely unknown. To identify potential targets of Notch in FL SLAM-LSKs, we used an ex vivo system in which SLAM-LSK cells were cultured on OP9-DL1 feeder cells, which generate lower levels of activated Notch1 than OP9-DL4 feeder cells due to differences in the affinity of Notch1 for these two ligands (Andrawes et al. 2013). The decision to use OP9-DL1 feeder cells and short time periods $(4 \mathrm{~h}$ and $10 \mathrm{~h})$ of coincubation was made in an effort to enrich for Notch target genes that are likely to be involved in HSC homeostasis rather than genes involved in induction of T-cell development. C57BL/6 E14.5 FLs were cultured on OP9DL1 stromal cells (Holmes and Zuniga-Pflucker 2009) in the presence of vehicle control (DMSO) for the "Notch on" state or GSI for the "Notch off" state. Treated SLAM-LSK HSCs were sorted, and microarray-based gene expression profiling was performed on mRNA harvested from these cells (Fig 6A).

The most prominent known Notch target gene affected by GSI treatment was Hes1, a result consistent with recent embryonic HSC profiling studies (McKinney-Freeman et al. 2012; Guiu et al. 2013) and studies using a Hes1GFP knock-in allele (Oh et al. 2013). Hes1 is known to have important functions in HSC fate specification and maintenance of T-ALL cells (Wendorff et al. 2010; Guiu et al. 2013), both of which may be relevant to the phenotypes observed in the $\triangle T$ TAD FL HSCs. We also identified Itgal (LFA-1) and Jag1 as GSI-sensitive genes following both 4-h and 10-h exposures to DL1. These results were validated independently by quantitative PCR (qPCR) on multiple biological replicates of the SLAM-LSK microarray experiment (Fig. 6B). The Notch ligand Jag1 is an important Notch target gene that is required for cardiac 


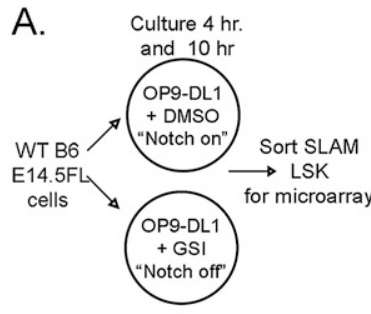

\begin{tabular}{|l|r|r|}
\hline $\begin{array}{c}\text { Gene } \\
\text { symbol }\end{array}$ & $\begin{array}{c}\text { Fold-Change } \\
\text { (GSI vs. DMSO) }\end{array}$ & q value (\%) \\
\hline${ }^{*} \mathrm{Hes} 1$ & -2.0 & 0 \\
\hline${ }^{*}$ Itgal & -1.4 & 19 \\
\hline${ }^{*} \mathrm{Efna1}$ & -1.4 & 19 \\
\hline${ }^{*} \mathrm{Gpr} 25$ & -2.3 & 51 \\
\hline Sh3gl3 & -1.5 & 52 \\
\hline${ }^{*}$ Jag1 & -1.5 & 52 \\
\hline
\end{tabular}

B.
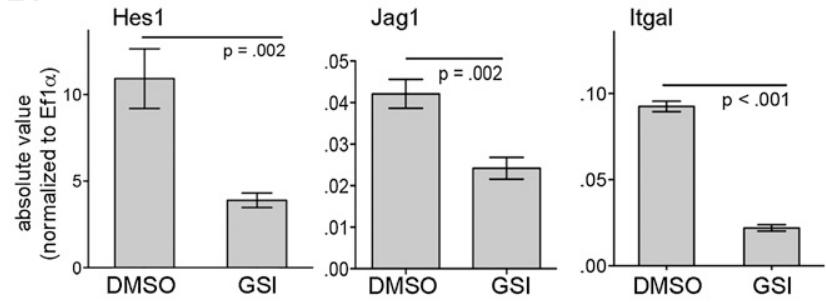

C.

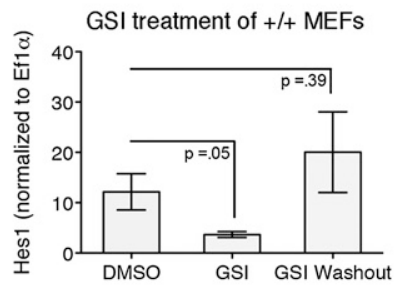

F. Hes1 Promoter sequence Biotin
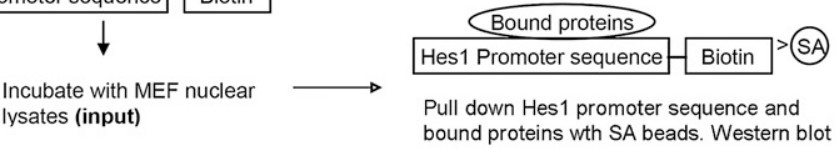
for specific proteins

D.

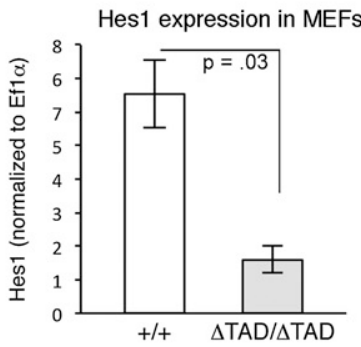

E.

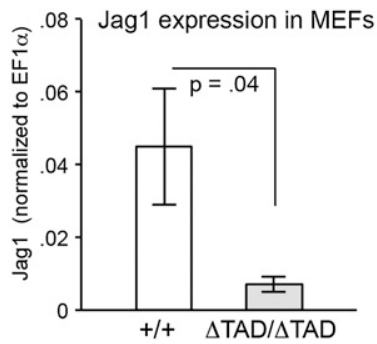

G.

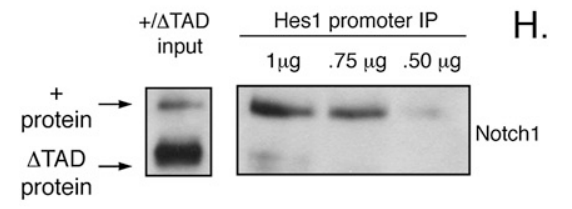

I.

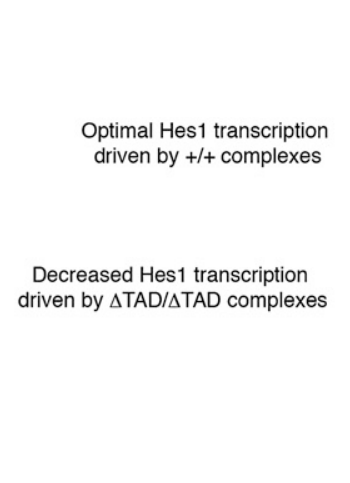

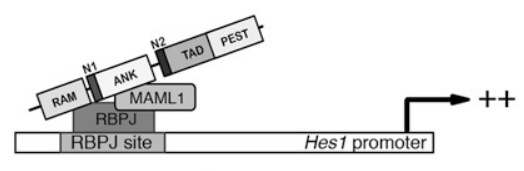

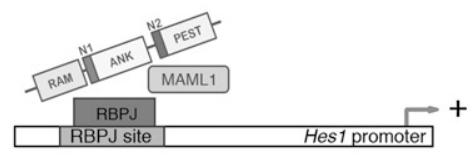

Figure 6. Decreased binding of the Notch1 transcriptional complex to the Hes1 promoter element in extracts prepared from $\Delta \mathrm{TAD}$ MEFs. (A) B6 E14.5 FL cells were cultured on OP9-DL1 cells for the times indicated $(4 \mathrm{~h}$ or $10 \mathrm{~h})$ in the presence of vehicle control (DSMO) in the "Notch on" state or GSI in the "Notch off" state. SLAM-LSKs were sorted from the coculture, and RNA obtained from the SLAM-LSKs was used for microarray analysis. Selected genes with decreased expression in the presence of GSI are shown. $\left({ }^{\star}\right)$ Genes with decreased expression after both $4 \mathrm{~h}$ and $10 \mathrm{~h}$ of treatment in the presence of GSI; $\mathrm{Q}$-value (percent) is used to express the false discovery rate. $(B)$ qPCR measurements from E14.5 FL SLAM-LSKs for Hes1, Jag1, and Itgal (Integrin- $\alpha /$ LFA-1) mRNA transcripts. All mRNA values were normalized to Ef1 $\alpha .(C)+/+$ MEFs were treated for $24 \mathrm{~h}$ with GSI or DMSO vehicle control. GSI was washed out at $18 \mathrm{~h}$, and cells were cultured in vehicle control for an additional $6 \mathrm{~h}$. Hes 1 mRNA was normalized to Ef1 $\alpha$ values. Graph is representative of four independent experiments. $(D, E)$ Graph of absolute values of Hes1 mRNA $(D)$ and $\operatorname{Jag} 1 \mathrm{mRNA}(E)$ from $\Delta$ TAD/ $\Delta \mathrm{TAD}$ and $+/+$ MEFs. Values were normalized to Ef $1 \alpha$ from four independent experiments for Hes 1 and two independent experiments for Jag1. $(F)$ Schematic for oligonucleotide immunoprecipitation. $(G)+/ \Delta$ TAD nuclear lysates were incubated with the Hes1 promoter oligonucleotide. (Left panel) Western blot for cleaved Notch1 (Val1744) in $+/ \Delta \mathrm{TAD}$ nuclear lysates (input) shows increased $\Delta \mathrm{TAD}$ protein relative to wild-type $(+)$ Notch 1 protein. At three concentrations $(1 \mu \mathrm{g}, 0.75 \mu \mathrm{g}$, and $0.5 \mu \mathrm{g})$ of oligonucleotide, wild-type protein binding to Hes1 promoter is enriched relative to $\triangle \mathrm{TAD}$ protein binding. $(H)$ Association of Mamll with Hes 1 oligonucleotide in the presence of $+/+,+/ \Delta \mathrm{TAD}$, or $\Delta \mathrm{TAD} / \Delta \mathrm{TAD}$ MEF nuclear lysates. Western blot for total Maml1 (left panel) and oligonucleotide-bound Mamll (right panel) from $+/+$ or $\Delta \mathrm{TAD} / \Delta \mathrm{TAD}$ nuclear lysates incubated with $1 \mu \mathrm{g}$ of Hes1 oligonucleotide. (I) Model of impaired formation and/or stabilization of Notch ternary complex with loss of the Notch1 TAD.

OFT development (High et al. 2009), while ItgaL may have functions in hematopoietic cell migration and adhesion (Peter and O'Toole 1995; Torensma et al. 1996; Asaumi et al. 2001)
We used MEFs to investigate the mechanism by which the Notch1 TAD influences gene transcription, as we were unable to obtain a sufficient number of HSCs for analysis. Similar to HSCs, we verified that Hes1 was 
sensitive to Notch inhibition in MEFs and, by performing a GSI washout assay, verified Hes1 as a direct Notch target in these cells (Fig. 6C). Analysis of Hes1 and Jag1 expression in MEFs originating from either $+/+$ or $\triangle \mathrm{TAD} /$ $\triangle$ TAD littermate embryos showed that Hes1 mRNA expression (Fig. 6D) and Jag1 mRNA expression (Fig. 6E) in $\triangle \mathrm{TAD} / \triangle \mathrm{TAD}$ MEFs was significantly lower than in $+/+$ MEFs, supporting our hypothesis that TAD loss negatively impacts expression of Notch targets.

Because Hes1 is a TAD-sensitive Notch1 target in MEFs, we used the Hes1 promoter as a model to better understand the function of the TAD. To determine whether absence of the Notch1 TAD influenced the binding of the Notch1 trimolecular complex to DNA targets, we performed pull-down experiments using a biotinylated oligonucleotide containing the Rbpj-binding sequence of the Hes1 promoter (Fig. 6F; Nam et al. 2007). Specificity of binding to the Hes1-biotinylated oligonucleotide was shown by the lack of Notch1 binding after mutation of the Rbpj-binding sites (Supplemental Fig. S5D). In order to compare binding of wild-type and $\triangle \mathrm{TAD}$ forms of Notch1 to the Hes1 promoter oligonucleotide, we used $+/ \triangle$ TAD MEFs. These cells express both forms of Notch1, with the $\Delta$ TAD protein (as previously observed in T cells) (Fig. 1D) being more abundant (Fig. $6 \mathrm{G})$. Nuclear lysates from $+/ \triangle \mathrm{TAD}$ MEFs were incubated with the biotinylated oligonucleotide to allow protein binding, and oligonucleotide-protein complexes were captured with streptavidin-coated beads, eluted, and analyzed on Western blots. Even though $+/ \Delta$ TAD MEFs have more $\triangle \mathrm{TAD}$ than wild-type Notch1 protein, binding of the wild-type protein to the oligonucleotide probe was greater, a difference that became strikingly obvious when the Hes1-biotinylated oligonucleotide was titrated out (Fig. 6G). Similarly, association of Maml1 with the Hes1 oligonucleotide was lower in extracts prepared from $\Delta \mathrm{TAD} / \triangle \mathrm{TAD}$ MEFs than wild-type MEFs, despite similar levels of Maml1 protein (Fig. 6H). Thus, absence of the TAD impairs the formation of the Notch transcriptional activation complex on response elements of Notch target genes, such as Hes1 (Fig. 6I).

\section{Discussion}

Successful ex vivo HSC expansion has proven to be a formidable challenge due to our limited understanding of the mechanisms regulating HSC expansion in vivo. The complicated origins and migratory development of HSCs have made this difficult task even more daunting, further confounded by the fact that the BM, the site of harvest for clinically relevant HSCs, provides a niche that supports adult HSC quiescence (Essers et al. 2009; Seita and Weissman 2010). In contrast, the FL is an important developmental site of HSC expansion (Ema and Nakauchi 2000); however, only a handful of factors, such as Sox17, Pu.1, Hoxa9, Gata2, and Cited2, have been shown to be critical for FL HSC homeostasis (Kim et al. 2004, 2007; Argiropoulos and Humphries 2007; Chen et al. 2007; de Pater et al. 2013). Recently, Notch1 was linked to Sox17, as it was identified as a direct Sox17 transcriptional target
(Clarke et al. 2013). Although Notch1 has been proposed to contribute to ex vivo HSC expansion and is expressed in the FL (Butler et al. 2010; McKinney-Freeman et al. 2012; Oh et al. 2013), it is not known whether Notch signaling has a role in the physiological expansion of HSCs. To date, the only known physiologic requirement for Notch in HSCs is to induce the emergence of the first definitive HSC in the E9.5 AGM.

We now report that Rbpj-dependent Notch1 signaling is a key regulator of FL HSC homeostasis. Previous studies of Notch signaling in fetal HSCs were hampered by the embryonic lethality that occurs at E9.5, prior to the onset of FL hematopoiesis. By deleting the Notch1 TAD, we generated a hypomorphic allele that allowed us to assay the requirement for Notch1 signaling in FL HSCs. Constitutive loss of the TAD resulted in a decrease of phenotypic HSCs in the FL, primarily due to increased apoptosis. In addition to the role of Notch signaling in FL HSC survival, our studies of purified $\triangle \mathrm{TAD}$ FL HSCs revealed a separate requirement for Notch1 signaling in FL HSC function. In these experiments, we sorted phenotypic FL LT-HSCs at a time in embryonic development (E14.5) after HSCs have successfully migrated to the FL and begun their maturation and expansion. We found that both homozygous and heterozygous loss of the Notch1 TAD impaired the function of purified FL HSCs in competitive reconstitution assays and that homozygous loss of the TAD also impaired HSC function in serial transplantation assays. As previous studies suggested that Notch signaling is not essential for adult HSC homeostasis (Maillard et al. 2008; Gao et al. 2009), the persistent HSC defect in serial transplantation suggests that inhibiting Notch in the early embryo induces LTHSC defects. Purified FL SLAM-LSK cells were used in these assays; thus, we believe the observed reconstitution defects are intrinsic to FL HSCs and inherent to the $\Delta \mathrm{TAD}$ mutation.

These findings were corroborated by experiments using Rbpj-deficient FL hematopoietic cells $\left(R b p j^{\mathrm{f} / \mathrm{f}}\right.$; Vav-Cre Rosa26YFP), where we observed similar defects in competitive reconstitution assays. The Vav-Cre mediated deletion of $R b p j$ occurs after HSCs have migrated to the FL; thus, the reconstitution defect reflects a requirement for Notch signaling in the FL and not in the generation of HSCs. Together, these two different murine models provide strong evidence for cell-autonomous functions of Notch signaling in FL HSC homeostasis.

While we focused on the hematopoietic defects in the $\Delta \mathrm{TAD} / \Delta \mathrm{TAD}$ embryos, these mice exhibited a variety of developmental defects, culminating in embryonic death. Through histological analysis of the $\Delta \mathrm{TAD} / \triangle \mathrm{TAD}$ embryos at E18.5, we demonstrated the importance of the Notch1 TAD in cardiac development. While it is known that Notch signaling is required for OFT formation, as evidenced by the association of mutations of the Notch signaling pathway with OFT defects and cardiac disease (Rochais et al. 2009; Rentschler et al. 2010), our data suggest that Notch1 is the critical receptor for proper OFT formation (Oda et al. 1997). Whether the effect on cardiac development results from qualitative or quanti- 
tative defects in embryonic Notch1 signaling remains to be determined.

The fact that $\Delta$ TAD mice do not die at E9.5, as occurs with the complete loss of Notch1, indicates that the TAD is not essential for all Notch functions. It follows that although the TAD plays an important role in enhancing Notch1 target gene expression, it is likely dispensable for expression of a subset of Notch targets that exceed a critical threshold for downstream functions. This is evident not only with our in vitro experiments using $\triangle T$ TAD MEFs, where Hes1 is expressed at reduced levels in TAD-deficient cells, but also in the defects in T-cell development seen in recipient mice reconstituted with $\Delta \mathrm{TAD} / \triangle \mathrm{TAD} H S C$ s and the failure of $\triangle \mathrm{TAD}$ alleles to drive leukemia in $\mathrm{BM}$ transduction experiments. (Aster et al. 2000). Our ex vivo analysis of GSI-sensitive targets in FL HSCs suggests that Notch targets in FL HSCs differ from $T$ cells and provide a starting point to elucidate how Notch functions in FL HSCs. It is tempting to speculate that conditions of stress, such as reconstitution in a competitive environment or serial transplantation, both of which require rapid expansion, necessitate increased Notch target gene expression, which is compromised in the absence of the TAD. While there are likely many Notch1 TAD-dependent genes, our profiling of FL HSC targets and initial studies using MEFs have identified Hes1 as a model target gene that is dependent on TAD function. Although the in vitro studies of the Notch1 TAD demonstrated its role in transcriptional activation (Kurooka et al. 1998; Kurooka and Honjo 2000), our data also reveal that the $\mathrm{TAD}$ is important for the proper assembly of the Notch1/Rbpi/Maml transcription complex (Gordon et al. 2008). Using $+/ \Delta$ TAD MEFS, we demonstrate preferential binding of Mamll and wild-type ICN1 to the Hes 1 promoter region even though the ICN1 $\triangle \mathrm{TAD}$ protein was present in excess. The decreased binding of Mamll is particularly striking, as Maml acts to stabilize the ICN/RBPJ complex in vitro (Nam et al. 2006; Wilson and Kovall 2006) and is required for target gene expression. The simplest explanation for these observations would be for the TAD to participate in intermolecular contacts that stabilize the complex. Although we know that the Ram-Ank domains of Notch1 are sufficient for formation of a stable Notch1 trimolecular complex in purified systems (Nam et al. 2006; Wilson and Kovall 2006), our finding raises the alternative possibility that cofactors that interact with the TAD promote the assembly of the core Notch1 transcriptional activation complex (Fig. 7).

Activation of the Notch pathway in vitro by ligand stimulation has been employed to expand hematopoietic progenitors from human cord blood HSCs, demonstrating that manipulation of the Notch pathway is a viable and effective therapeutic strategy (Varnum-Finney et al. 2011). Ex vivo expansion of murine HSCs has also been achieved using a method that relies on the presentation of Notch ligands on endothelial cells (Butler et al. 2010). Although these examples point to the potential that manipulation of the Notch signaling pathway has for HSC expansion, prior studies had not provided a clear indication that physiologic Notch signaling is essential for HSC homeostasis beyond establishment of the first

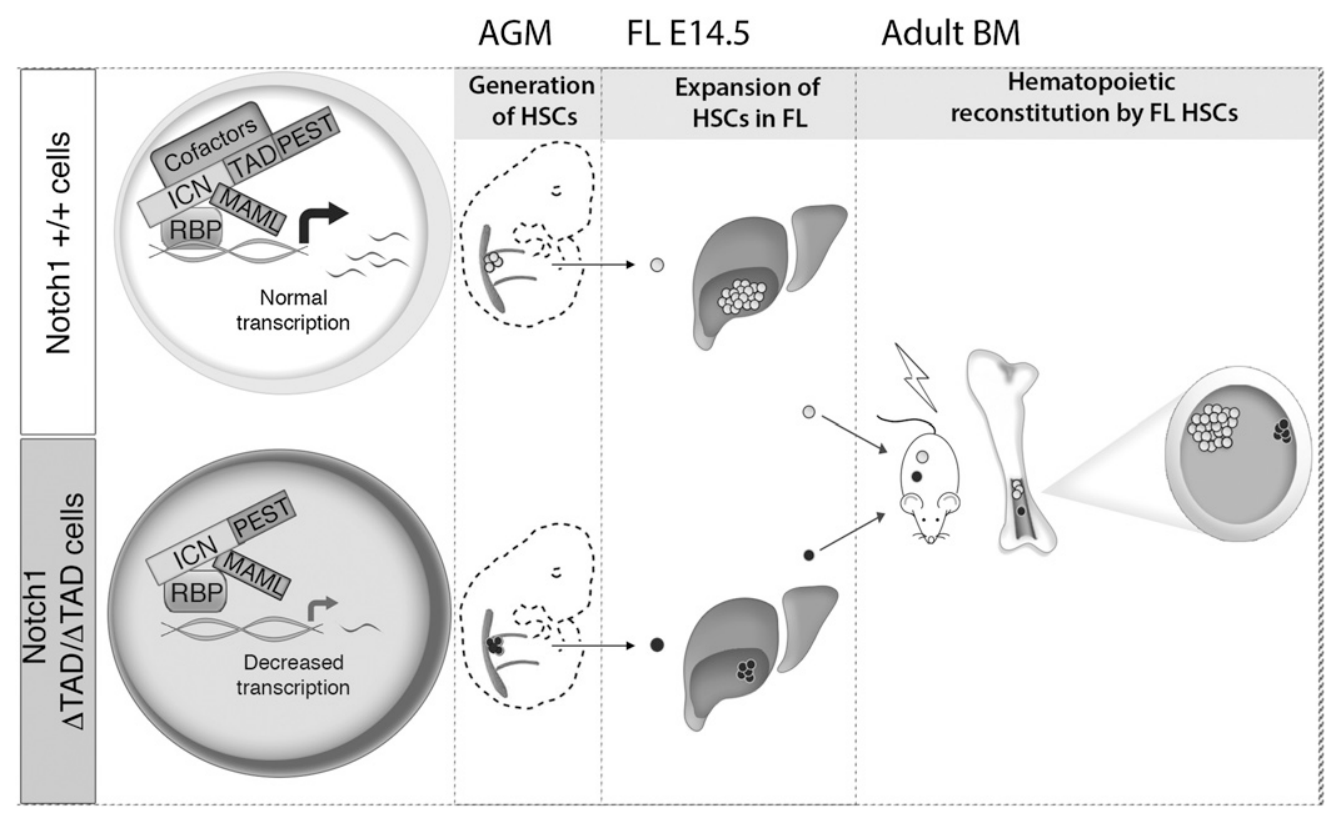

Figure 7. Model of Notch $1+/+$ and $\Delta \mathrm{TAD} / \Delta \mathrm{TAD}$ FL development and function. (Top panel) Formation of the Notch1 transcriptional complex promotes optimal transcription of Notch target genes, allowing for generation of HSCs from the AGM, expansion of HSCs in the FL, and robust function of FL HSCs in competitive transplants. Lack of the Notch1 TAD (bottom panel) impairs formation of the Notch1 transcriptional complex (top panel), resulting in reduced transcription of Notch target genes. Lack of the TAD allows for generation of HSCs from the AGM but leads to a decreased number of HSCs in the FL as well as impaired function of FL HSCs in competitive transplants. 
definitive LT-HSC. Our data show that Notch1 exerts important functions in FL HSCs. Since the current attempts to expand HSCs ex vivo recapitulate embryonic hematopoiesis (Clarke et al. 2013), identification of Notch as a critical player in this process provides a new rationale for studying Notch in this clinically relevant context. Recent data suggest that enhanced Notch signals in the adult BM promote HSC differentiation at the expense of self-renewal (Chiang et al. 2013; Lee et al. 2013). Our current data show that in the FL, enhanced Notch signals are compatible with both HSC expansion and self-renewal. While a substantial effort is necessary to fully understand these context-specific differences in Notch signaling in fetal and adult hematopoiesis, our current findings extend our understanding of the crucial cross-talk between hematopoietic development and Notch biology with regard to FL HSC expansion and maturation.

\section{Materials and methods}

Mice

$\Delta \mathrm{TAD} / \Delta \mathrm{TAD}$ mice were generated by mutation of the Notch1 gene in embryonic stem cells using homologous recombination. The Notch1 TAD is from base pairs 43091-43699 of the mouse Notch1 gene, between the XhoI and SacI restriction sites. The Notch1 TAD deletion is from base pairs 6580-7188 of the mouse Notchl coding sequence (this region encompasses the glutamic acid at amino acid position 2193 to valine at amino acid 2396). A gene targeting vector was constructed to mediate PCRdirected deletion of the TAD from mouse Notch1. The targeting vector also introduced an EcoRI site in the mutant TAD exon. Thus, the amino acid sequence resulting from the mutant TAD region was MLSPVDSLGILSSAANGH. The targeting vector was transfected into mouse embryonic stem cells, and clones with deletion of the Notch1 TAD were injected into blastocysts. Mice with germline transmission of the Notch1 TAD deletion were selected for breeding and backcrossed to the C57BL/6 background for more than six generations. The Extract-N-Amp tissue PCR kit (Sigma, XNAT2) was used to genotype adult and embryonic tissue. Primer sequences are provided in the Supplemental Material. Notch $1^{\text {in32 }}$ mice (Swiatek et al. 1994) on a C57BL/6 background were provided by Jan Kitajewski (Columbia University). B6-Ly5.2/Cr (strain code 01B96) mice were obtained from the Frederick National Laboratory of the National Cancer Institute. CD $45.1^{+} / \mathrm{CD} 45.2^{+}$mice were obtained from the first generation of matings between C57BL/6 and B6-Ly5.2/Cr mice. Rbpi ${ }^{\mathrm{f} / \mathrm{f}}$; Vav1-CreRosa26YFP mice were on a C57BL/6 background. Vav1-Cre mice (Stadtfeld and Graf 2005) were provided by Thomas Graf (Centre for Genomic Regulation [CRG], Barcelona). Genomic DNA from yolk sac tissue was used for genotyping by PCR. All mice were housed in specific pathogen-free facilities at the University of Pennsylvania or the Parc Recerca Biomedica Barcelona (PRBB) animal facility. Experiments were performed according to the guidelines from the National Institutes of Health with approved protocols from the University of Pennsylvania Animal Care and Use Committee or with approved protocols from PRBB Committee and Generalitat de Catalunya.

\section{Cell culture}

MEFs were generated following a standard protocol (Conner 2001). Cells were grown in DMEM (Cellgro) supplemented with
10\% fetal bovine serum (FBS) (Gibco), 1\% penicillin/streptomycin (Gibco), 1\% L-glutamine (Gibco), $100 \mu \mathrm{M}$ 2-mercaptoethanol (Sigma), and 1\% NEAA (Gibco). MEFs were not used beyond passage 25. Primary CD4 cells were cultured for $48 \mathrm{~h}$ in the presence of T-cell-depleted splenocytes (as a source of antigenpresenting cells) at a T-cell:splenocyte ratio of 1:4. Soluble antiCD3 (eBioscience, 145-2C11) and anti-CD28 (eBioscience, 37.51) were added at $1 \mu \mathrm{g} / \mathrm{mL}$. T-cell culture medium was IMDM (Gibco) supplemented with 10\% FBS, 1\% penicillin/streptomycin, $1 \%$ L-glutamine, and $5 \mathrm{ng} / \mathrm{mL}$ rIL-2 (Peprotech). OP9-DL1 cells were maintained in OP9 medium: MEM-Alpha (Gibco) supplemented with $20 \%$ FBS (Hyclone), $1 \%$ penicillin/streptomycin, $1 \%$ L-glutamine, and $1 \%$ NEAA. For short-term culture of HSCs, $5 \times 10^{5}$ OP9-DL1 cells were seeded in 10 -cm plates in OP9 medium with 5\% FBS. Red blood cell-lysed E14.5 FL cells $\left(15 \times 10^{6}\right)$ were added to OP9-DL1 cells and cultured in OP9 medium with $5 \%$ FBS, $5 \mathrm{ng} / \mathrm{mL}$ Flt3 (PeproTech), and $100 \mathrm{ng} / \mathrm{mL}$ $\mathrm{mSCF}$ (PeproTech) in the presence of $1 \mu \mathrm{M}$ GSI (EMD, $\gamma$-Secretase Inhibitor XXI, Compound E) or DMSO for $4 \mathrm{~h}$ or $10 \mathrm{~h}$. Nonadherent cells were collected and stained for CD45.2 and SLAM-LSK markers. GFP ${ }^{-}$(to exclude contaminating OP9-DL1 cells) CD45.2 $2^{+}$SLAM-LSK cells were sorted into $200 \mu \mathrm{L}$ of Arturus pico pure extraction buffer for RNA preparation.

\section{6 cell culture and transduction}

8946 cells were maintained in RPMI supplemented with $10 \%$ FBS (Hyclone), $2 \mathrm{mM}$ L-glutamine, $1 \mathrm{mM}$ sodium pyruvate, and $1 \%$ penicillin/streptomycin. Migr1 and Mig-ICN1 retroviral vectors (constructed with the human ICN1 coding sequence) have been previously described (Aster et al. 2000). For generation of the Mig-ICN1 $\triangle \mathrm{TAD}$ vector, the region containing base pairs 6609-7262 (corresponding to 218 amino acids) was deleted from human ICN1 coding sequence by site-directed mutagenesis of Mig-ICN1 (Stragene QuikChange site-directed mutagenesis kit). Production of high-titer retrovirus MigR1 control, Mig-ICN1, and Mig-ICN1 $\triangle$ TAD were produced as described (Pear et al. 1996). Cells were centrifuged with the appropriate amount of viral supernatant and $4 \mu \mathrm{g} / \mathrm{mL}$ hexadimethidrine bromide (Sigma) at $2500 \mathrm{rpm}$ for $90 \mathrm{~min}$ at $25^{\circ} \mathrm{C}$. $\mathrm{GFP}^{+}$cells were sorted $48 \mathrm{~h}$ posttransduction. Sorted cells were treated with $20 \mathrm{ng} / \mathrm{mL}$ doxycycline for $24 \mathrm{~h}$ to suppress the human MYC transgene, a time point that did not affect 8946 cell viability. Cells were then harvested for RNA preparation, and qPCR was performed to measure mRNA expression of the indicated genes. mRNA expression values are absolute and were normalized to Efla. GFP expression after doxycycline treatment was also confirmed by flow cytometry

\section{Luciferase assays}

U20S cells were seeded $1 \times 10^{4}$ cells per well in 96-well plates, with 24 wells per condition. Four hours after seeding, the medium was changed, and cells were transfected with Fugene6 and 25-50 ng of plasmid DNA per well, including the pcDNA3 (EV), pcDNA3-ICN, pcDNA3-ICN- $\triangle T A D$, pCMV-MAML, and internal transfection control pRL-TK. One day post-transfection, the medium was changed, and $48 \mathrm{~h}$ post-transfection, the cells were lysed, and firefly luciferase levels were measured in one step with Britelite plus (Perkin-Elmer). Renilla luciferase was measured with Stop-n-Glo reagent from Promega. All readings were made using a Promega Glomax 96-microplate Luminometer at 1-sec intervals.

\section{Western analysis}

Nuclear lysates were prepared using the Active Motif nuclear complex coimmunoprecipitation kit (54001), and whole-cell 
lysates were prepared with RIPA buffer; protease inhibitors were included for both. Protein concentration was determined with the Bio-Rad protein assay dye reagent (Bio-Rad). Proteins were separated using SDS-PAGE and transferred to PVDF membranes. Antibodies used for Western blot were cleaved Notch1 (Val1744) antibody (Cell Signaling Technology, no. 2421), MAML1 (D3E9) rabbit mAb (Cell Signaling Technology, no. 11959), $\beta$-actin (Sigma), and secondary anti-mouse-HRP (Pierce) or anti-rabbitHRP (Pierce). Blots were visualized with SuperSignal west pico chemilumenscence (Thermo Scientific) or SuperSignal west femto chemilumenscence substrate (Thermo Scientific).

\section{Oligonucleotide pull-down}

MEFs generated from embryos of the same litter were isolated as described above and grown to similar early passages (passages 6-9). Adherent MEFs were trypsinized, washed twice in PBS, centrifuged, and resuspended in hypotonic buffer for nuclear extraction per the manufacturer's recommendation (Active Motif, no. 54001). Nuclear protein lysates were quantified by Bio-Rad Bradford assay. One-hundred micrograms to $150 \mu \mathrm{g}$ of protein was incubated with $2 \mu \mathrm{g} / \mu \mathrm{L}$ annealed biotinylated oligonucleotides for $4-12 \mathrm{~h}$ at $4^{\circ} \mathrm{C}$ with rotation. Lysate and biotinylated oligonucleotide mixture was supplemented with $1 \mu \mathrm{g} / \mu \mathrm{L}$ poly-IC, and the volume was brought up to $500 \mu \mathrm{L}$ by addition of binding buffer ( $12 \mathrm{mM}$ HEPES, $4 \mathrm{mM}$ Tris at $\mathrm{pH} 8.0$, containing $60 \mathrm{mM} \mathrm{KCl}, 5 \%$ glycerol, $500 \mu \mathrm{M}$ EDTA, $1 \mathrm{mM} \mathrm{DTT}$, $1 \times$ protease inhibitors [Roche]). Streptavidin beads (Invitrogen) were washed twice in binding buffer, and 25-30 $\mu \mathrm{L}$ of beads was added to the nuclear lysate and biotinylated oligonucleotide mixture and incubated for $4-8 \mathrm{~h}$ at $4^{\circ} \mathrm{C}$ with rotation (Puente et al. 2011). The incubated mixture was centrifuged at $6000 \mathrm{rpm}$ for $1 \mathrm{~min}$, and the supernatant was collected and stored at $-80^{\circ} \mathrm{C}$. Beads were washed four times in $1 \mathrm{~mL}$ of binding buffer, resuspended in $25 \mu \mathrm{L}$ of Laemmli buffer, boiled for $10 \mathrm{~min}$ at $100^{\circ} \mathrm{C}$, and centrifuged at $13,000 \mathrm{rpm}$ for $10 \mathrm{~min}$. Eluted proteins were separated by SDS-PAGE in a $7 \%-8 \%$ gel, and Western blot was prepared with cleaved Notch1 (Val1744) antibody as described above. Oligonucleotide sequences are provided in the Supplemental Material (Supplemental Table S1).

\section{Flow cytometry and cell sorting}

AGM, FL, or BM cells (from adult tibia and femurs) were harvested and resuspended in PBS supplemented with $10 \%$ heat-inactivated FBS (Gibco) and 1\% penicillin/streptomycin (Gibco). Antibodies used for identification of HSCs in E11.5 AGM and E11.5 FL cells were CD144 Alexa Fluor 647 (eBioscience, BV13), CD45.2 V450 (BD, 104), 7-AAD (eBioscience), and TER-119 PerCP-Cy5.5 (BD, TER-119). E11.5 AGM singlecell suspensions were prepared by treating with collagenase type I (Sigma) prior to staining. For SLAM-LSK staining, the antibodies used were CD45.2 FITC (BD, 104), Sca-1 (Ly6A/E) PerCP-Cy5.5 or FITC (eBioscience, D7), CD48 APC or phycoerythrin (PE) (eBioscience, HM48-1), CD150 PE-Cy7 (Biolegend, TC15-12F12.2), c-Kit APC-Cy7 (eBioscience, 2B8), and DAPI (BD). Lineage markers for BM cells were B220 (BD, RA3-6B2), Gr-1 (BD, RB6-8C5), CD3 (BD, 17A2), TER-119 (BD, TER-119). Mac-1 (BD, M1/70), CDllC (BD, HL3), NK1.1 (BD, PK136), CD4 (BD, RM4-5), CD8 $\alpha$ (BD, 53-6.7), and CD19 (BD, 1D3), all conjugated to $\mathrm{PE}$ unless indicated otherwise. Lineage markers used for FL cells were B220 (BD, RA3-6B2), Gr-1 (BD, RB6-8C5), CD3 (BD, 17A2), and TER-119 (BD, TER-119), all conjugated to $\mathrm{PE}$ unless indicated otherwise. For intracellular cleaved Notch1 detection, cells were first stained for surface markers and then fixed and permeabilized using the eBioscience transcription factor staining buffer set (00-5523). Fixed/permeabilized cells were incubated with primary rabbit antibody to Notch1 cleaved at Val1744 (Cell Signaling, no. 2421) at a 1:100 dilution in permeabilization buffer and secondary Alexa Fluor 488 goat anti-rabbit $\operatorname{IgG}(\mathrm{H}+\mathrm{L}$, Invitrogen) at a 1:300 dilution in permeabilization buffer. Surface Notch was detected by anti-Notch1 (eBioscience, 22E5) conjugated to APC.

For Annexin V detection, cells were first stained for SLAMLSK markers (lineage markers were conjugated to V450) and then incubated with Annexin $\mathrm{V}(\mathrm{PE})$ in binding buffer provided in the Annexin V apoptosis detection kit (eBioscience, 88-8102-72). 7AAD viability staining solution (eBioscience) was added to cells prior to analysis. Lin $^{+}$FL cells were used as an internal control to determine the percentage of Annexin $\mathrm{V}^{+}$FL LSKs and SLAMLSKs in each sample. Values were determined by subtracting the mean percentage of $+/+$ Annexin $\mathrm{V}^{+}$Lin $^{+}$cells (calculated as percent Annexin $\mathrm{V}^{+}$cells \pm SEM, which was $\left.1.600 \pm 0.147 ; n=4\right)$ from the mean percentage of Annexin $\mathrm{V}^{+}+/+$SLAM-LSKs and by subtracting the mean percentage of $\triangle \mathrm{TAD} / \triangle \mathrm{TAD}$ Annexin $\mathrm{V}^{+}$ $\mathrm{Lin}^{+}$cells $(4.025 \pm 0.728 ; n=4)$ from the mean percentage of Annexin $\mathrm{V}^{+} \Delta \mathrm{TAD} / \Delta \mathrm{TAD}$ SLAM-LSKs.

Cell cycle analysis was performed by first staining for SLAMLSK markers; cells were then fixed and permeabilized using the eBioscience transcription factor staining buffer set followed by incubation with DAPI and Ki-67 FITC (eBioscience SolA15) at a 1:200 dilution. Cells were not stained for CD45.2 for cell cycle analysis. Cells were analyzed on a BD LSRII equipped with an ultraviolet laser. Acquisition was performed with DAPI on a linear scale. Acquisition for flow cytometry was performed on a LSRII (Becton Dickinson). All cells were sorted on a BD FACSAria into PBS supplemented with $2 \%$ FBS and $1 \%$ penicillin/streptomycin. All flow cytometry data were analyzed with Flowjo (TreeStar). LTHSC numbers were calculated from the number of cells within the live cell gate. LSK $\left(\mathrm{DAPI}^{-} \mathrm{Lin}^{-} \mathrm{Scal}^{+} \mathrm{Kit}^{+}\right)$or SLAM-LSK $\left(\mathrm{DAPI}^{-} \mathrm{Lin}^{-} \mathrm{Scal}^{+} \mathrm{Kit}^{+} \mathrm{CD} 48^{-} \mathrm{CD} 150^{+}\right.$) cells from E14.5 FLs were acquired on a BD LSRII flow cytometer.

\section{HSC transplants}

For noncompetitive transplants, unfractionated FL cells or sorted SLAM-LSK FL cells from E14.5 embryos (C57BL/6) were transplanted intravenously with congenic splenocyte support cells into congenic recipients. Red blood cells were lysed with ACK lysing buffer (Lonza). For competitive transplants of $\triangle \mathrm{TAD} / \Delta \mathrm{TAD}$ cells, unfractionated FL cells $\left(1 \times 10^{6}\right.$ cells $)$ or sorted CD45.2 ${ }^{+}$SLAM-LSK FL cells (350 cells) from E14.5 embryos (C57BL/6) were transplanted intravenously into congenic recipients with equal numbers of unfractionated FL or sorted BM SLAM-LSKs. Live/dead cells were identified by DAPI staining. For secondary transplants, 1000 donor-derived +/+ or $\Delta \mathrm{TAD} / \Delta \mathrm{TAD} \mathrm{CD} 45.2^{+}$SLAM-LSKs were sorted from the $\mathrm{BM}$ of primary transplant recipients (primary transplant was noncompetitive E14.5 FL cell transplant) and transplanted with congenic splenocyte support cells into congenic recipients. For $R b p i^{\mathrm{f} / \mathrm{f}}$; Vav-Cre Rosa26YFP competitive FL transplants, $1 \times 10^{4}$ nucleated E14.5 FL cells from $R b p i^{\mathrm{f} / \mathrm{f}}$; Vav-Cre Rosa26YFP or $\mathrm{Rbpi}^{+/+}$; Vav-Cre Rosa26YFP were transplanted with $2 \times 10^{5}$ nucleated BM competitor cells. Rbpi deletion in FLengrafted cells was confirmed by PCR on genomic DNA prepared from purified sorted $\mathrm{BM} \mathrm{YFP}^{+}$cells obtained 4 mo post-transplantation. All cells were washed with cold PBS prior to injection. Mice were maintained on antibiotic water for $2 \mathrm{wk}$ post-transplant.

\section{Statistical analysis}

For $\triangle \mathrm{TAD} / \Delta \mathrm{TAD}$ competitive $\mathrm{FL}$ transplants, regression analysis was performed to evaluate the difference of mean CD45.2 
percentage in reconstituted recipients. Experiment and genotype were treated as independent factors. For noncompetitive FL transplants, two-way analysis of variance was used to calculate significance of mean CD45.2 reconstitution. For $R b p i^{\mathrm{f} / \mathrm{f}}$; Vav-Cre Rosa26YFP competitive FL transplants, the data were transformed using the arc-sine transformation of the observation/100. The $t$-test was used to evaluate the difference between the transformed mean reconstitution from the $R b p f^{\mathrm{f} / \mathrm{f}}$; Vav-Cre Rosa26YFP and $\mathrm{Rbpi}^{+/+}$; Vav-Cre Rosa26YFP cells. Unless noted, the Student's $t$-test was used to calculate the $P$-value in all other experiments. Welch-Satterthwaite's method was used when there was evidence of unequal variances in the two groups. All error bars represent SEM. All statistical analyses were performed with SAS/STAT software version 9.3 of the SAS system for Windows and GraphPad Prism version 5 for Mac.

qPCR

RNA was extracted using the Qiagen RNeasy minikit or microkit. For SLAM-LSKs, cells were sorted into $200 \mu \mathrm{L}$ of Arcturus pico pure extraction buffer, and RNA was prepared using the Arcturus pico pure RNA extraction kit (Life Technologies, KIT0204). cDNA was synthesized from RNA with the SuperScript II kit (Invitrogen). Transcripts were amplified with SYBR Green PCR master mix (Applied Biosystems), and qPCR was performed on the ABI Prism 7900HT system (Applied Biosystems). Absolute quantities of mRNA were normalized to ef $1 \alpha$. Primer sequences are provided in the Supplemental Material.

\section{Mircroarray analysis of SLAM-LSKS}

SLAM-LSKs were sorted into $200 \mu \mathrm{L}$ of Arcturus pico pure extraction buffer. RNA from SLAM-LSKs was extracted using the Arcturus pico pure RNA extraction kit. Microarray services were provided by the University of Pennsylvania Molecular Profiling Facility, including quality control tests of the total RNA samples by Agilent Bioanalyzer and nanodrop spectrophotometry. All protocols were conducted as described in the NuGEN Ovation pico WTA system version 2 user's guide and the Affymetrix GeneChip expression analysis technical manual. Briefly, 10 ng of total RNA was converted to first strand cDNA using reverse transcriptase primed by poly $(\mathrm{dT})$ and random oligomers that incorporated an RNA priming region. Second strand cDNA synthesis was followed by ribo-SPIA linear amplification of each transcript using an isothermal reaction with RNase, RNA primer, and DNA polymerase, and the resulting ssDNA was assessed by Bioanalyzer and then fragmented and biotinylated by terminal transferase end labeling. ssDNA yields ranged from 7.8 to $11.3 \mu \mathrm{g}$, and $5.5 \mu \mathrm{g}$ of labeled ssDNA was added to Affymetrix hybridization cocktails, heated for $2 \mathrm{~min}$ at $99^{\circ} \mathrm{C}$, and hybridized for $16 \mathrm{~h}$ at $45^{\circ} \mathrm{C}$ to Mouse Gene 2.0 st GeneChips (Affymetrix). The microarrays were then washed at low $(6 \times$ SSPE) and high (100 mM MES, 0.1 M NaCl) stringency and stained with streptavidin-PE. Fluorescence was amplified by adding biotinylated anti-streptavidin and an additional aliquot of streptavidin-PE stain. A confocal scanner was used to collect fluorescence signal after excitation at $570 \mathrm{~nm}$.

\section{Data collection analysis}

The final microarray analysis reflects data from seven biologically independent experiments (for the 4-h GSI time point) and four independent experiments (for the 10-h GSI time point). All data obtained from the 4-h and 10-h GSI time courses were analyzed independently of each other. CEL files were analyzed using Partek Genomics suite. Separately for each analysis,
Affymetrix CEL files (containing probe intensities) were exported from Command Console software and imported into the Partek Genomics suite (version 6.6, Partek, Inc.), where RMA was applied, yielding normalized, $\log _{2}$-transformed signal intensities. Transcript identifications were filtered to exclude technical controls, leaving 34,365 identifications for differential expression analysis. To find differentially expressed genes, SAM (Significance Analysis for Microarrays, samr version 2.0, Stanford University) was applied using a two-class (GSI vs. DMSO) paired (by experiment) design. Fold change and Q-value (representing false discovery rate) were calculated for all transcript identifications. Genes were prioritized based on Q-value and fold decrease in GSI versus DMSO treatment. Excel data sets are available in the Supplemental Material, and raw data files will be provided on the Gene Expression Omnibus database, accession no. GSE53713

\section{Histology}

Samples were fixed overnight with $4 \%$ paraformaldehyde, dehydrated through an ethanol series, and subsequently paraffinembedded and sectioned. Hematoxylin and eosin staining was performed using standard protocols. Images were analyzed using Adobe Photoshop (sizing, brightness, or contrast adjustments, etc.). Brightness and contrast was adjusted linearly across the entire image for any particular image.

\section{Acknowledgments}

We thank Kristin Toscano for technical assistance, and Avinash Bhandoola and Will Bailis for thoughtful discussion. The following cores at the University of Pennsylvania contributed to this study: mouse husbandry (University Laboratory Animal Resources), the Abramson Cancer Center Flow Cytometry Core (P30-CA016520), the University of Pennsyvania Molecular Profiling Core (P30-DK090969), and the Abramson Family Cancer Research Institute Cores. This work was supported by T32CA009140 and T32GM007229 to D.M.G.; a Leukemia and Lymphoma Society Fellow Award and T32HL007843 to K.V.P.; a Financial Peace University fellowship (AP2008-01883) to T.D.; a National Marfan Foundation Award to R.J.; a Career Award for Medical Scientists from the Burroughs Wellcome Fund and K08 HL107449 to S.R.; grants from the National Institutes of Health to W.S.P. (R01AI047833), J.C.A. and W.S.P. (P01CA119070), and J.E. (U01HL100405); and grants from the Spanish government (PLE09-0111 and SAF2010-15450) and Red Temática de Investigación Cooperativa en Cáncer (RD12/0036/0054) to A.B.

\section{References}

Andrawes MB, Xu X, Liu H, Ficarro SB, Marto JA, Aster JC, Blacklow SC. 2013. Intrinsic selectivity of Notch 1 for Deltalike 4 over Delta-like 1. J Biol Chem 288: 25477-25489.

Argiropoulos B, Humphries RK. 2007. Hox genes in hematopoiesis and leukemogenesis. Oncogene 26: 6766-6776.

Artavanis-Tsakonas S, Rand MD, Lake RJ. 1999. Notch signaling: cell fate control and signal integration in development. Science 284: $770-776$.

Asaumi N, Omoto E, Mahmut N, Katayama Y, Takeda K, Shinagawa K, Harada M. 2001. Very late antigen-5 and leukocyte function-associated antigen-1 are critical for early stage hematopoietic progenitor cell homing. Ann Hematol 80: $387-392$.

Aster JC, Xu L, Karnell FG, Patriub V, Pui JC, Pear WS. 2000. Essential roles for ankyrin repeat and transactivation do- 
mains in induction of T-cell leukemia by Notch1. Mol Cell Biol 20: 7505-7515.

Butler JM, Nolan DJ, Vertes EL, Varnum-Finney B, Kobayashi H, Hooper AT, Seandel M, Shido K, White IA, Kobayashi M, et al. 2010. Endothelial cells are essential for the self-renewal and repopulation of Notch-dependent hematopoietic stem cells. Cell Stem Cell 6: 251-264.

Chen Y, Haviernik P, Bunting KD, Yang YC. 2007. Cited2 is required for normal hematopoiesis in the murine fetal liver. Blood 110: 2889-2898.

Chiang MY, Xu ML, Histen G, Shestova O, Roy M, Nam Y, Blacklow SC, Sacks DB, Pear WS, Aster JC. 2006. Identification of a conserved negative regulatory sequence that influences the leukemogenic activity of NOTCH1. Mol Cell Biol 26: 6261-6271.

Chiang MY, Shestova O, Xu L, Aster JC, Pear WS. 2013. Divergent effects of supraphysiologic Notch signals on leukemia stem cells and hematopoietic stem cells. Blood 121: 905-917.

Clarke RL, Yzaguirre AD, Yashiro-Ohtani Y, Bondue A, Blanpain C, Pear WS, Speck NA, Keller G. 2013. The expression of Sox17 identifies and regulates haemogenic endothelium. Nat Cell Biol 15: 502-510.

Conlon RA, Reaume AG, Rossant J. 1995. Notch1 is required for the coordinate segmentation of somites. Development 121: 1533-1545.

Conner DA. 2001. Mouse embryo fibroblast (MEF) feeder cell preparation. Curr Protoc Mol Biol 51: 23.2.1-23.2.7.

de Pater E, Kaimakis P, Vink CS, Yokomizo T, Yamada-Inagawa $\mathrm{T}$, van der Linden $\mathrm{R}$, Kartalaei PS, Camper SA, Speck N, Dzierzak E. 2013. Gata2 is required for HSC generation and survival. I Exp Med 210: 2843-2850.

Dzierzak E, Speck NA. 2008. Of lineage and legacy: the development of mammalian hematopoietic stem cells. Nat Immunol 9: 129-136.

Ema H, Nakauchi H. 2000. Expansion of hematopoietic stem cells in the developing liver of a mouse embryo. Blood 95: 2284-2288.

Essers MA, Offner S, Blanco-Bose WE, Waibler Z, Kalinke U, Duchosal MA, Trumpp A. 2009. IFN $\alpha$ activates dormant haematopoietic stem cells in vivo. Nature 458: 904-908.

Fiorini E, Merck E, Wilson A, Ferrero I, Jiang W, Koch U, Auderset F, Laurenti E, Tacchini-Cottier F, Pierres M, et al. 2009. Dynamic regulation of Notch 1 and Notch 2 surface expression during $\mathrm{T}$ cell development and activation revealed by novel monoclonal antibodies. I Immunol 183: 7212-7222.

Fryer CI, Lamar E, Turbachova I, Kintner C, Jones KA. 2002. Mastermind mediates chromatin-specific transcription and turnover of the Notch enhancer complex. Genes Dev 16: 1397-1411.

Fryer CJ, White JB, Jones KA. 2004. Mastermind recruits CycC:CDK8 to phosphorylate the Notch ICD and coordinate activation with turnover. Mol Cell 16: 509-520.

Gao J, Graves S, Koch U, Liu S, Jankovic V, Buonamici S, El Andaloussi A, Nimer SD, Kee BL, Taichman R, et al. 2009. Hedgehog signaling is dispensable for adult hematopoietic stem cell function. Cell Stem Cell 4: 548-558.

Gordon WR, Arnett KL, Blacklow SC. 2008. The molecular logic of Notch signaling - a structural and biochemical perspective. J Cell Sci 121: 3109-3119.

Guiu J, Shimizu R, D'altri T, Fraser ST, Hatakeyama J, Bresnick EH, Kageyama R, Dzierzak E, Yamamoto M, Espinosa L, et al. 2013. Hes repressors are essential regulators of hematopoietic stem cell development downstream of Notch signaling. J Exp Med 210: 71-84.
Hadland BK, Huppert SS, Kanungo J, Xue Y, Jiang R, Gridley T, Conlon RA, Cheng AM, Kopan R, Longmore GD. 2004. A requirement for Notch 1 distinguishes 2 phases of definitive hematopoiesis during development. Blood 104: 3097-3105.

High F, Epstein JA. 2007. Signalling pathways regulating cardiac neural crest migration and differentiation. Novartis Found Symp 283: 152-161.

High FA, Zhang M, Proweller A, Tu L, Parmacek MS, Pear WS, Epstein JA. 2007. An essential role for Notch in neural crest during cardiovascular development and smooth muscle differentiation. J Clin Invest 117: 353-363.

High FA, Jain R, Stoller JZ, Antonucci NB, Lu MM, Loomes KM, Kaestner KH, Pear WS, Epstein JA. 2009. Murine Jagged1/ Notch signaling in the second heart field orchestrates Fgf8 expression and tissue-tissue interactions during outflow tract development. J Clin Invest 119: 1986-1996.

Holmes R, Zuniga-Pflucker JC. 2009. The OP9-DL1 system: generation of T-lymphocytes from embryonic or hematopoietic stem cells in vitro. Cold Spring Harb Protoc 2009: pdb.prot5156.

Huang EY, Gallegos AM, Richards SM, Lehar SM, Bevan MJ. 2003. Surface expression of Notch1 on thymocytes: correlation with the double-negative to double-positive transition. J Immunol 171: 2296-2304.

Kiel MJ, Yilmaz OH, Iwashita T, Terhorst C, Morrison SJ. 2005. SLAM family receptors distinguish hematopoietic stem and progenitor cells and reveal endothelial niches for stem cells. Cell 121: 1109-1121.

Kieusseian A, Brunet de la Grange P, Burlen-Defranoux O, Godin I, Cumano A. 2012. Immature hematopoietic stem cells undergo maturation in the fetal liver. Development 139: 3521-3530.

Kim HG, de Guzman CG, Swindle CS, Cotta CV, Gartland L, Scott EW, Klug CA. 2004. The ETS family transcription factor PU.1 is necessary for the maintenance of fetal liver hematopoietic stem cells. Blood 104: 3894-3900.

Kim I, He S, Yilmaz OH, Kiel MJ, Morrison SJ. 2006. Enhanced purification of fetal liver hematopoietic stem cells using SLAM family receptors. Blood 108: 737-744.

Kim I, Saunders TL, Morrison SJ. 2007. Sox17 dependence distinguishes the transcriptional regulation of fetal from adult hematopoietic stem cells. Cell 130: 470-483.

Koo BK, Lim HS, Song R, Yoon MJ, Yoon KJ, Moon JS, Kim YW, Kwon MC, Yoo KW, Kong MP, et al. 2005. Mind bomb 1 is essential for generating functional Notch ligands to activate Notch. Development 132: 3459-3470.

Kopan R, Ilagan MX. 2009. The canonical Notch signaling pathway: unfolding the activation mechanism. Cell 137: 216-233.

Kovall RA, Blacklow SC. 2010. Mechanistic insights into Notch receptor signaling from structural and biochemical studies. Curr Top Dev Biol 92: 31-71.

Krebs LT, Xue Y, Norton CR, Shutter JR, Maguire M, Sundberg JP, Gallahan D, Closson V, Kitajewski J, Callahan R, et al. 2000. Notch signaling is essential for vascular morphogenesis in mice. Genes Dev 14: 1343-1352.

Kumano K, Chiba S, Kunisato A, Sata M, Saito T, NakagamiYamaguchi E, Yamaguchi T, Masuda S, Shimizu K, Takahashi T, et al. 2003. Notch1 but not Notch2 is essential for generating hematopoietic stem cells from endothelial cells. Immunity 18: 699-711.

Kurooka H, Honjo T. 2000. Functional interaction between the mouse Notch1 intracellular region and histone acetyltransferases PCAF and GCN5. J Biol Chem 275: 17211-17220.

Kurooka H, Kuroda K, Honjo T. 1998. Roles of the ankyrin repeats and C-terminal region of the mouse Notch1 intracellular region. Nucleic Acids Res 26: 5448-5455. 
Lawson ND, Scheer N, Pham VN, Kim CH, Chitnis AB, Campos-Ortega JA, Weinstein BM. 2001. Notch signaling is required for arterial-venous differentiation during embryonic vascular development. Development 128: 3675-3683.

Lee SU, Maeda M, Ishikawa Y, Li SM, Wilson A, Jubb AM, Sakurai N, Weng L, Fiorini E, Radtke F, et al. 2013. LRFmediated Dll4 repression in erythroblasts is necessary for hematopoietic stem cell maintenance. Blood 121: 918-929.

Maillard I, Koch U, Dumortier A, Shestova O, Xu L, Sai H, Pross SE, Aster JC, Bhandoola A, Radtke F, et al. 2008. Canonical Notch signaling is dispensable for the maintenance of adult hematopoietic stem cells. Cell Stem Cell 2: 356-366.

Mancini SJ, Mantei N, Dumortier A, Suter U, MacDonald HR, Radtke F. 2005. Jaggedl-dependent Notch signaling is dispensable for hematopoietic stem cell self-renewal and differentiation. Blood 105: 2340-2342.

McKinney-Freeman S, Cahan P, Li H, Lacadie SA, Huang HT, Curran M, Loewer S, Naveiras O, Kathrein KL, Konantz M, et al. 2012. The transcriptional landscape of hematopoietic stem cell ontogeny. Cell Stem Cell 11: 701-714.

Morrison SJ, Hemmati HD, Wandycz AM, Weissman IL. 1995. The purification and characterization of fetal liver hematopoietic stem cells. Proc Natl Acad Sci 92: 10302-10306.

Nam Y, Sliz P, Song L, Aster JC, Blacklow SC. 2006. Structural basis for cooperativity in recruitment of MAML coactivators to Notch transcription complexes. Cell 124: 973-983.

Nam Y, Sliz P, Pear WS, Aster JC, Blacklow SC. 2007. Cooperative assembly of higher-order Notch complexes functions as a switch to induce transcription. Proc Natl Acad Sci 104: $2103-2108$

North TE, de Bruijn MF, Stacy T, Talebian L, Lind E, Robin C, Binder M, Dzierzak E, Speck NA. 2002. Runx1 expression marks long-term repopulating hematopoietic stem cells in the midgestation mouse embryo. Immunity 16: 661-672.

Oda T, Elkahloun AG, Pike BL, Okajima K, Krantz ID, Genin A, Piccoli DA, Meltzer PS, Spinner NB, Collins FS, et al. 1997. Mutations in the human Jaggedl gene are responsible for Alagille syndrome. Nat Genet 16: 235-242.

Ogilvy S, Metcalf D, Gibson L, Bath ML, Harris AW, Adams JM. 1999. Promoter elements of vav drive transgene expression in vivo throughout the hematopoietic compartment. Blood 94: 1855-1863.

Oh P, Lobry C, Gao J, Tikhonova A, Loizou E, Manent J, van Handel B, Ibrahim S, Greve J, Mikkola H, et al. 2013. In vivo mapping of Notch pathway activity in normal and stress hematopoiesis. Cell Stem Cell 13: 190-204.

Oka C, Nakano T, Wakeham A, de la Pompa JL, Mori C, Sakai T, Okazaki S, Kawaichi M, Shiota K, Mak TW, et al. 1995. Disruption of the mouse RBP-JK gene results in early embryonic death. Development 121: 3291-3301.

O'Neil J, Grim J, Strack P, Rao S, Tibbitts D, Winter C, Hardwick J, Welcker M, Meijerink JP, Pieters R, et al. 2007. FBW7 mutations in leukemic cells mediate NOTCH pathway activation and resistance to $\gamma$-secretase inhibitors. J Exp Med 204: 1813-1824.

Ong CT, Cheng HT, Chang LW, Ohtsuka T, Kageyama R, Stormo GD, Kopan R. 2006. Target selectivity of vertebrate Notch proteins. Collaboration between discrete domains and CSL-binding site architecture determines activation probability. J Biol Chem 281: 5106-5119.

Oswald F, Tauber B, Dobner T, Bourteele S, Kostezka U, Adler G, Liptay S, Schmid RM. 2001. p300 acts as a transcriptional coactivator for mammalian Notch-1. Mol Cell Biol 21: 77617774.

Pear WS, Aster JC, Scott ML, Hasserijian RP, Soffer B, Sklar J, Baltimore D. 1996. Exclusive development of T cell neo- plasms in mice transplanted with bone marrow expressing activated Notch alleles. J Exp Med 183: 2283-2291.

Peter K, O'Toole TE. 1995. Modulation of cell adhesion by changes in $\alpha \mathrm{L} \beta 2$ (LFA-1, CD11a/CD18) cytoplasmic domain/cytoskeleton interaction. J Exp Med 181: 315-326.

Puente XS, Pinyol M, Quesada V, Conde L, Ordonez GR, Villamor N, Escaramis G, Jares P, Bea S, Gonzalez-Diaz M, et al. 2011. Whole-genome sequencing identifies recurrent mutations in chronic lymphocytic leukaemia. Nature 475: 101-105.

Rentschler S, Jain R, Epstein JA. 2010. Tissue-tissue interactions during morphogenesis of the outflow tract. Pediatr Cardiol 31: 408-413.

Rochais F, Dandonneau M, Mesbah K, Jarry T, Mattei MG, Kelly RG. 2009. Hes 1 is expressed in the second heart field and is required for outflow tract development. PLOS ONE 4: e6267.

Schmitt TM, Zuniga-Pflucker JC. 2002. Induction of T cell development from hematopoietic progenitor cells by Deltalike-1 in vitro. Immunity 17: 749-756.

Seita J, Weissman IL. 2010. Hematopoietic stem cell: selfrenewal versus differentiation. Wiley Interdiscip Rev Syst Biol Med 2: 640-653.

Stadtfeld M, Graf T. 2005. Assessing the role of hematopoietic plasticity for endothelial and hepatocyte development by non-invasive lineage tracing. Development 132: 203-213.

Swiatek PJ, Lindsell CE, del Amo FF, Weinmaster G, Gridley T. 1994. Notch1 is essential for postimplantation development in mice. Genes Dev 8: 707-719.

Tamura K, Taniguchi Y, Minoguchi S, Sakai T, Tun T, Furukawa T, Honjo T. 1995. Physical interaction between a novel domain of the receptor Notch and the transcription factor RBP-JK/Su(H). Curr Biol 5: 1416-1423.

Tanigaki K, Tsuji M, Yamamoto N, Han H, Tsukada J, Inoue H, Kubo M, Honjo T. 2004. Regulation of $\alpha \beta / \gamma \delta$ T cell lineage commitment and peripheral T cell responses by Notch/RBP-J signaling. Immunity 20: 611-622.

Taoudi S, Morrison AM, Inoue H, Gribi R, Ure J, Medvinsky A. 2005. Progressive divergence of definitive haematopoietic stem cells from the endothelial compartment does not depend on contact with the foetal liver. Development 132: 4179-4191.

Thompson BJ, Buonamici S, Sulis ML, Palomero T, Vilimas T, Basso G, Ferrando A, Aifantis I. 2007. The SCFFBW7 ubiquitin ligase complex as a tumor suppressor in $\mathrm{T}$ cell leukemia. J Exp Med 204: 1825-1835.

Torensma R, Raymakers RA, van Kooyk Y, Figdor CG. 1996. Induction of LFA-1 on pluripotent $\mathrm{CD} 34^{+}$bone marrow cells does not affect lineage commitment. Blood 87: 41204128.

Varnum-Finney B, Halasz LM, Sun M, Gridley T, Radtke F, Bernstein ID. 2011. Notch2 governs the rate of generation of mouse long- and short-term repopulating stem cells. J Clin Invest 121: 1207-1216.

Wallberg AE, Pedersen K, Lendahl U, Roeder RG. 2002. p300 and PCAF act cooperatively to mediate transcriptional activation from chromatin templates by Notch intracellular domains in vitro. Mol Cell Biol 22: 7812-7819.

Wendorff AA, Koch U, Wunderlich FT, Wirth S, Dubey C, Bruning JC, MacDonald HR, Radtke F. 2010. Hes1 is a critical but context-dependent mediator of canonical Notch signaling in lymphocyte development and transformation. Immunity 33: 671-684.

Weng AP, Ferrando AA, Lee W, Morris JPt, Silverman LB, Sanchez-Irizarry C, Blacklow SC, Look AT, Aster JC. 2004. Activating mutations of NOTCH1 in human $\mathrm{T}$ cell acute lymphoblastic leukemia. Science 306: 269-271. 
Weng AP, Millholland JM, Yashiro-Ohtani Y, Arcangeli ML, Lau A, Wai C, Del Bianco C, Rodriguez CG, Sai H, Tobias J, et al. 2006. c-Myc is an important direct target of Notch1 in T-cell acute lymphoblastic leukemia/lymphoma. Genes Dev 20: 2096-2109.

Wilson JJ, Kovall RA. 2006. Crystal structure of the CSL-NotchMastermind ternary complex bound to DNA. Cell 124: 985996.

Wolfer A, Wilson A, Nemir M, MacDonald HR, Radtke F. 2002. Inactivation of Notch1 impairs VDJ $\beta$ rearrangement and allows pre-TCR-independent survival of early $\alpha \beta$ lineage thymocytes. Immunity 16: 869-879.

Yashiro-Ohtani Y, He Y, Ohtani T, Jones ME, Shestova O, Xu L, Fang TC, Chiang MY, Intlekofer AM, Blacklow SC, et al. 2009. Pre-TCR signaling inactivates Notch1 transcription by antagonizing E2A. Genes Dev 23: 1665-1676.

Yokomizo T, Dzierzak E. 2010. Three-dimensional cartography of hematopoietic clusters in the vasculature of whole mouse embryos. Development 137: 3651-3661. 


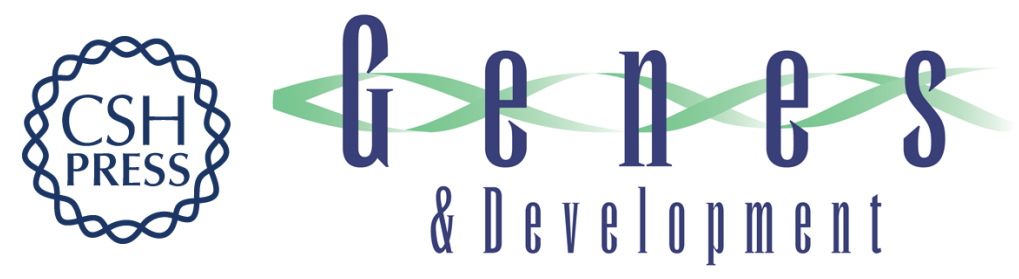

\section{The Notch1 transcriptional activation domain is required for development and reveals a novel role for Notch1 signaling in fetal hematopoietic stem cells}

Dawson M. Gerhardt, Kostandin V. Pajcini, Teresa D'altri, et al.

Genes Dev. 2014, 28:

Access the most recent version at doi:10.1101/gad.227496.113

Supplemental Material

References

Creative

Commons

License

Email Alerting

Service
http://genesdev.cshlp.org/content/suppl/2014/03/13/28.6.576.DC1

This article cites 79 articles, 44 of which can be accessed free at: http://genesdev.cshlp.org/content/28/6/576.full.html\#ref-list-1

This article is distributed exclusively by Cold Spring Harbor Laboratory Press for the first six months after the full-issue publication date (see http://genesdev.cshlp.org/site/misc/terms.xhtml). After six months, it is available under a Creative Commons License (Attribution-NonCommercial 4.0 International), as described at http://creativecommons.org/licenses/by-nc/4.0/.

Receive free email alerts when new articles cite this article - sign up in the box at the top right corner of the article or click here.

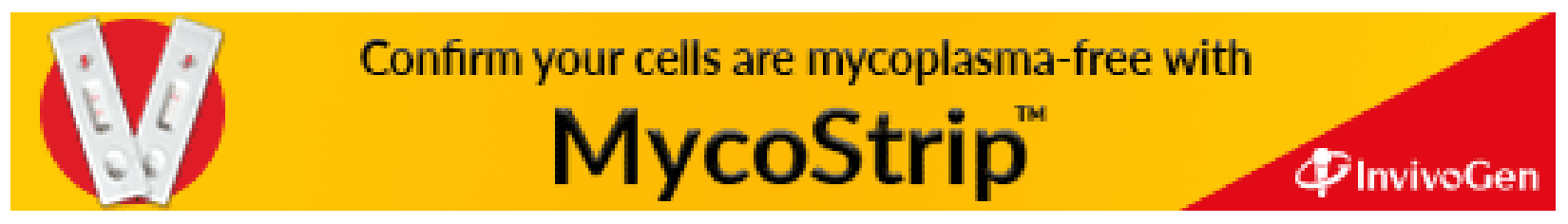

